\title{
Observing and Simulating Wind-Turbine Wakes During the Evening Transition
}

\author{
Joseph C. Y. Lee ${ }^{1}$ D J Julie K. Lundquist ${ }^{1}$
}

Received: 28 April 2016/ Accepted: 26 April 2017 / Published online: 25 May 2017

(C) The Author(s) 2017. This article is an open access publication

\begin{abstract}
Wind-turbine-wake evolution during the evening transition introduces variability to wind-farm power production at a time of day typically characterized by high electricity demand. During the evening transition, the atmosphere evolves from an unstable to a stable regime, and vertical stratification of the wind profile develops as the residual planetary boundary layer decouples from the surface layer. The evolution of wind-turbine wakes during the evening transition is examined from two perspectives: wake observations from single turbines, and simulations of multiple turbine wakes using the mesoscale Weather Research and Forecasting (WRF) model. Throughout the evening transition, the wake's wind-speed deficit and turbulence enhancement are confined within the rotor layer when the atmospheric stability changes from unstable to stable. The height variations of maximum upwind-downwind differences of wind speed and turbulence intensity gradually decrease during the evening transition. After verifying the WRF-model-simulated upwind wind speed, wind direction and turbulent kinetic energy profiles with observations, the wind-farm-scale wake evolution during the evening transition is investigated using the WRF-model wind-farm parametrization scheme. As the evening progresses, due to the presence of the wind farm, the modelled hub-height wind-speed deficit monotonically increases, the relative turbulence enhancement at hub height grows by $50 \%$, and the downwind surface sensible heat flux increases, reducing surface cooling. Overall, the intensifying wakes from upwind turbines respond to the evolving atmospheric boundary layer during the evening transition, and undermine the power production of downwind turbines in the evening.
\end{abstract}

Keywords Evening transition - Lidar - Wind energy · Wind-farm parametrization · Wind-turbine wakes

Joseph C. Y. Lee

chle6805@colorado.edu

1 Department of Atmospheric and Oceanic Sciences, University of Colorado Boulder, 311 UCB,

Boulder, CO 80309-0311, USA 


\section{Introduction}

\subsection{The Evening Boundary Layer and Turbine Wakes}

Daily electricity demand typically increases in the early evening, making the balance of power supply and demand a challenge during this period (McLoughlin et al. 2013). Households require higher power demand in the evening, while solar-power generation is diminishing. The wind-power capacity of the world continues to grow, and providing stable electricity supply via wind power remains an ongoing challenge to power-grid operators due to the variability of wind-energy production. Therefore, it is important to understand utilityscale wind-turbine-wake behaviour during the evening transition because wakes undermine downwind wind-power production. An enhanced understanding of wake evolution during the evening transition can also be helpful in other situations. For example, offshore wind farms often experience land and sea breezes such that coastal flow undergoes a similar transition to that of a continental evening transition (Angevine 2007) and can affect wind-power production.

The unique characteristics of the evening transition have been explored in the past in terms of changes in temperature, turbulence, and surface fluxes (Deardorff 1974a, b; Mahrt 1981; Nieuwstadt and Brost 1986; Edwards et al. 2006). The evening transition is the period during which the daytime unstable atmosphere evolves into the nocturnal stable boundary layer, where a distinct transition is observed during conditions with quiescent synoptic forcing. Acevedo and Fitzjarrald (2001) identified the "early evening transition" as the period when the planetary boundary layer (PBL) is decoupled from the surface layer, and leads to a temperature decrease, a wind-speed reduction, and an increase in water vapour mixing ratio near the surface. Lothon et al. (2014) defined the evening transition as the period after the surface sensible heat flux $\left(Q_{H}\right)$ reaches zero and before the establishment of the nocturnal stable layer. The evening transition can be further described by the temperature profile evolution in the PBL, with the presence of a near-surface temperature inversion as an indication of a decoupled nocturnal boundary layer (Grimsdell and Angevine 2002; Angevine 2007). As a result, a temperature inversion near the surface forms at the start of the evening transition, usually at least $1 \mathrm{~h}$ before sunset (Grimsdell and Angevine 2002).

Changes in turbulence also suggest the onset of the evening transition. An abrupt decay in turbulent kinetic energy (TKE), associated with the collapse of daytime turbulence, and the sign changes in the surface heat flux $Q_{H}$, are indicators of the "early evening transition" (Nadeau et al. 2011). The delay between the time when $Q_{H}$ becomes negative and the TKE decay has been quantified previously (Nieuwstadt and Brost 1986; Sorbjan 1997; BlayCarreras et al. 2014). Sastre et al. (2015) also demonstrated that the wind speed reaches a minimum around the time of sunset, and the turbulence time scale decreases during the evening transition.

In this study, we define the evening transition as the time at which the near-surface atmospheric stability undergoes transition from convective to stable, and the value of the surface heat flux $Q_{H}$ changes sign. Though alternative approaches have been used previously, we find this definition the most appropriate. Using this approach, we can determine an unambiguous evening transition in the chosen case study as $Q_{H}$ declines monotonically.

The evening transition presents a scientific challenge for wind-energy forecasting, since the flow becomes increasingly stratified during the evening transition, making the forecasting of wind-power production a challenge (Sanderse et al. 2011). While summer nocturnal lowlevel jets increase boundary-layer wind speeds (Vanderwende et al. 2015; Bonin et al. 2015), providing ample wind resources during the summer in the Great Plains, the power deficit, 
the reduction in power production of downwind turbines located within the wakes, increases with atmospheric stability (Hansen et al. 2012). New approaches to yawing upwind turbines in order to improve the power production of downwind turbines (Fleming et al. 2015, 2016) require accurate wake prediction. The difficulties posed by uncertain flows, substantial wind resources, large power deficits and possible wake manipulation potentially affect wind-power production in the evening.

Wake features in different atmospheric stability regimes have been widely studied, but wake behaviour during the evening transition remains unexplored. Early wake observations (Magnusson and Smedman 1994) concluded that the wind-speed deficit and the downwind turbulence generation are greatest in a stable atmosphere, as wakes erode minimally due to the lack of background turbulence. Wake behaviour depends not only on thermal stability but also on the upwind wind profile, and wind-tunnel experiments have demonstrated that inhomogeneous upwind flow disturbs the vertical symmetry of the downwind wind-speed deficit and turbulence (Chamorro and Porté-Agel 2009). The wind-speed deficit and the vortices in the wake also affect wake meandering and wake expansion from the turbine centreline (Howard et al. 2015).

\subsection{Turbine-Wake Simulations}

Comparisons of lidar measurements to large-eddy simulations (LES) with a generalized actuator disk (GAD) model in the Weather Research and Forecasting (WRF) model are capable of representing wake-deficit characteristics qualitatively (Mirocha et al. 2014, 2015; Aitken et al. 2014b). GAD model results have indicated that turbine wakes expand more in the horizontal direction than vertically (Mirocha et al. 2014). At a downwind distance of 6.5 times the rotor diameter $(D)$, the flow experiences up to $25 \%$ wind-speed reduction in a weakly convective regime (Mirocha et al. 2014). LES has also revealed that the wind-speed deficit extends further downwind, the turbulence generation decreases and the overall wake recovers more slowly in the stable PBL than in the unstable PBL (Abkar and Porté-Agel 2015; Bhaganagar and Debnath 2015; Mirocha et al. 2015). However, modelled turbine wakes grow horizontally twice as rapidly, and the wake meanders from the wake centreline to a greater extent in convective than in stable conditions (Abkar and Porté-Agel 2015; Vanderwende et al. 2016a). Unfortunately, examining the wake behaviour of a sizable wind farm using LES is computationally expensive (Churchfield et al. 2012), and the simulation of wind-farm impacts using mesoscale meteorological models is more practical.

Various approaches of representing wind farms in mesoscale models have been explored. For example, surface roughness has been locally increased in climate models to represent the drag effects of wind turbines (Keith et al. 2004; Frandsen et al. 2009); however, this method ignores turbine impacts on flow phenomena such as below-rotor speed-up within the lowest few hundred metres above ground level (a.g.l.) (Fitch et al. 2012). Further, the use of the roughness approach generates turbine-induced daytime heating and nocturnal cooling (Fitch et al. 2013b) rather than the observed nocturnal heating (Zhou et al. 2012; Rajewski et al. 2013, 2014). Alternatively, the fact that the turbine rotor disk is elevated is considered by using flow-dependent parameters to introduce the effects of turbines into the flow, resulting in turbine-induced elevated drag and an increase in turbulence intensity. When the inflow speed increases, both the induced drag and the turbine-power production increase, according to the associated turbine-power curve (Blahak et al. 2010; Baidya Roy 2011). In addition to the power curve, the use of the turbine thrust coefficient, which also varies with wind speed, provides a more accurate estimate of turbine drag and power loss (Fitch et al. 2012). This 
elevated-drag approach has been shown to reproduce correct nocturnal heating from wind farms (Fitch et al. 2013b).

Here, we use the mesoscale WRF model's wind-farm parametrization (WFP) scheme (Fitch et al. 2012; Fitch 2015) to simulate an actual wind farm. The WFP scheme is based on Blahak et al. (2010) and Baidya Roy (2011), and uses the turbine-thrust coefficients. In the WFP scheme, wind turbines are represented as a momentum sink and a source of turbulence at the altitudes at which turbine blades are located (Fitch et al. 2012; Fitch 2015). The WFP scheme estimates local turbine drag based on the thrust coefficient, which is the total fraction of kinetic energy extracted from the atmosphere as a function of wind speed. The modelled generation of TKE varies with wind speed, and the momentum sink converts a fraction of kinetic energy into electricity generation (Fitch et al. 2012). Unlike LES, the WFP scheme does not account for wake meandering or the wake effects on turbines in the same grid cell (Fitch et al. 2012). The grid-averaged wake thus includes some uncertainty in characterizing wakes (Vanderwende et al. 2016a). While the WFP scheme tends to underestimate the power deficit of downwind turbines, it is capable of qualitatively reproducing wind-farm impacts in different atmospheric stability conditions (Jiménez et al. 2015), and has been used to explore the impact of surface roughness on wind-farm production (Vanderwende and Lundquist 2016b).

Using the WFP scheme in the WRF model, wake evolution during the evening transition was briefly examined in Fitch et al. (2013a), though without comparison to observations. In Fitch et al. (2013a), the background boundary-layer wind speed increased throughout the evening transition, leading to greater wind-speed deficits and turbulence enhancement within the rotor layer and to heights up to $2 D$ above the rotor layer. Even though the power production increased during the evening transition, downwind vertical mixing was inhibited within the growing stable layer, leading to strong and persistent wakes. However, Fitch et al. (2013a) did not include a comprehensive discussion on the response of wakes to atmospheric stability changes during the evening transition, the topic that we address herein.

Wake evolution during the evening stability change has not been addressed in previous work; therefore, we examine turbine-wake evolution during the transition using both measurements and simulations. The observations and the modelling approach are described in Sect. 2, and we discuss the observations of individual turbine wakes for one well-observed case study (Sect. 3.1). Then, we compare the upwind observed profiles to the simulated background atmosphere in the WRF model, so as to validate the modelled inflows (Sect. 3.2). Next, the aggregate wake evolution during the evening transition caused by multiple wind turbines is further explored using the WFP scheme (Sect. 3.3). The observations and model results demonstrate that, through the evening transition, increasingly persistent wakes develop, as quantified by downwind wind-speed deficits and turbulence generation. The evolving atmosphere during the evening transition potentially poses challenges in the prediction of wind-power production.

\section{Data and Methods}

\subsection{Wake Observations}

Assessing the meteorological impacts of wind-turbine wakes and their subsequent impact on power production during the evening transition requires detailed atmospheric measurements of the upwind and downwind flow. To explore wake behaviour, the Crop/Wind Energy EXperiment 2011 (CWEX-11) collected wind observations in a 200-turbine wind farm in central Iowa from June to August 2011 (Rajewski et al. 2013, 2014; Rhodes and Lundquist 
Fig. 1 Topography map of CWEX-11. Blue diamonds, red circles and yellow triangles represent the wind turbines (WT), the NCAR surface-flux stations (NCAR) and the WindCube lidars (WC) respectively. The instrument locations were constant throughout the whole campaign. The contours represent the elevation above sea level in metres

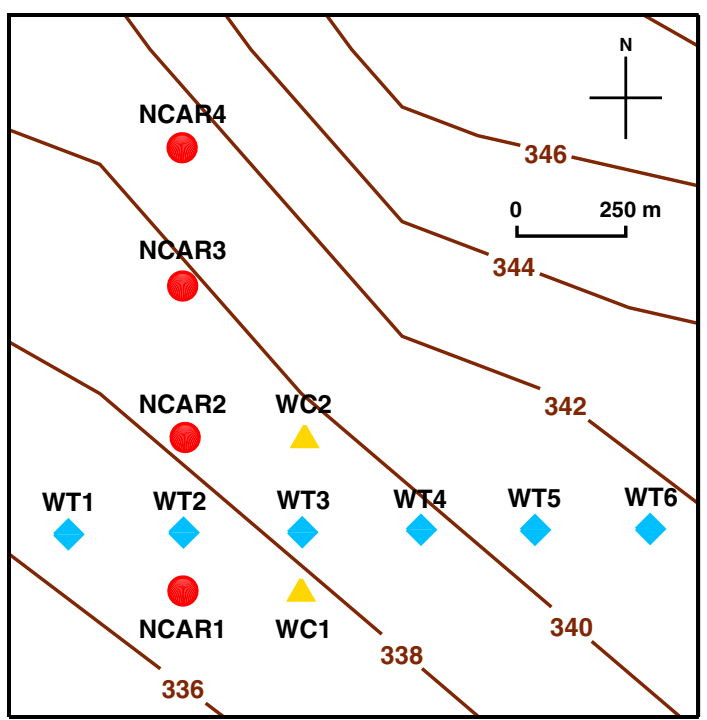

2013). The hub height and the rotor diameter of the 1.5-MW super-long extended (SLE) wind turbines manufactured by General Electric are 80 and $77 \mathrm{~m}$ respectively, with the rotor layer extending from approximately 40 to $120 \mathrm{~m}$ a.g.l. (Rajewski et al. 2013). The cut-in, rated and cut-out speeds of the turbines are $3.5,14$ and $25 \mathrm{~m} \mathrm{~s}^{-1}$ respectively. High-resolution wind profiles upwind and downwind of a row of wind turbines were measured using two vertical-profiling Doppler wind lidars and four surface-flux towers. Note that we present time as both local time (LT) and Coordinated Universal Time (UTC), where LT $+5 \mathrm{~h}=$ UTC.

The WindCube lidars measured velocity components at nominally $0.25 \mathrm{~Hz}$ from 40 to 220 $\mathrm{m}$ a.g.1., while the flux towers collected $20-\mathrm{Hz}$ measurements of near-surface wind speed and direction, the surface heat flux $Q_{H}$, virtual temperature, and water vapour density at $4.5 \mathrm{~m}$ a.g.l. Since the prevailing wind direction at the site is southerly, the instruments were located directly north $(250 \mathrm{~m}$, about $3 D)$ and south $(164 \mathrm{~m}$, about $2 D)$ of a row of east-west oriented turbines (Fig. 1). The two furthest downwind flux towers were positioned $664 \mathrm{~m}$ (about 8.6D) and $1036 \mathrm{~m}$ (about $13.5 \mathrm{D}$ ) north of the row of turbines. As a result, turbine-wake impacts can be quantified via comparison of the upwind and downwind sites, including wind-speed deficit, near-surface temperature change, turbulence intensity (TI) and TKE enhancement. The turbulence intensity can be calculated as

$$
T I=\frac{\sqrt{\sigma_{u}^{2}+\sigma_{v}^{2}}}{\bar{U}},
$$

and the lidar-estimated TKE $(\bar{e})$ can be calculated as

$$
\bar{e}=0.5\left(\sigma_{u}^{2}+\sigma_{v}^{2}+\sigma_{w}^{2}\right),
$$

where $\bar{U}$ is the average wind speed, and $\sigma^{2}$ are the 2-min averaged variances of the $u, v, w$ velocity components (Stull 1988).

Pulsed lidars (WC1 and WC2) use the Doppler beam swinging method to take wind measurements at all specified altitudes based on the same pulse, by comparing the backscattering arrival time at different heights to the pulse initialization time (Courtney et al. 2008). The method assumes flow homogeneity over a horizontal area so as to retrieve horizontal and ver- 
tical wind speeds. In CWEX-11, the wind components are averaged every 2 min to quantify the associated variability. However, the errors in cross-stream and vertical velocity components from near-wake lidar measurements at a distance $2 \mathrm{D}$ downwind can be significant in stable conditions (Lundquist et al. 2015). Besides, the WindCube lidars do not measure atmospheric turbulence precisely due to the spatial separation of the data points along the line-of-sight and in the conical section (Sathe et al. 2011). As a result, the observed 2-min averaged turbulence parameters describe only the variances as observed by the lidar, rather than the evolution of small-scale turbulence. Nonetheless, the wake effects due to an individual turbine can still be described by contrasting the lidar-measured 2-min averaged wind speed and lidar TKE, when the upwind flow is southerly and most of the wake overlaps the lidar scanning volume.

Wind speed outside of the downwind wake edges is occasionally measured when slight wind-direction changes divert part of the wake outside of the lidar's sampling volume. At hub height, the cross-stream $1-\mathrm{Hz}$ beams from the downwind lidar measure wind components beyond the wake edges when the inflow wind direction deviates by more than $3.19^{\circ}$ on each side of the $180^{\circ}$ wind direction. Downwind wind-speed measurements derived from along-stream lidar beams are not affected by this caveat. However, the sampling beyond the wake edges introduces a source of uncertainty for downwind turbulence measurements, as the cross-stream observations are incorporated into such measurements.

The sonic anemometers and gas analyzers installed at the National Center for Atmospheric Research (NCAR) surface-flux stations provide $20-\mathrm{Hz}$ measurements of wind velocity, virtual temperature and water vapour density at $4.5 \mathrm{~m}$ a.g.l. (Rajewski et al. 2013). The sonic wind vectors are rotated to correct for instrument tilt using the planar fit technique (Wilczak et al. 2001). The flux stations also record 2- and 10-m air temperature, 2-m air pressure, and 2-m relative humidity at a rate of $1 \mathrm{~Hz}$. In addition, located between the lidars and the NCAR flux stations, two upwind and downwind flux towers from Iowa State University (ISU) also provide 5-min precipitation measurements. Since the locations of the NCAR flux towers are more advantageous than the ISU tower locations in observing wakes in southerly flow, only high-resolution data from the NCAR flux stations are analyzed herein.

\subsection{Case Study Description}

A case study for 9 July 2011 is chosen to illustrate wake effects during the evening transition, based on several criteria. First, both lidars must report data without interruption between 1500 and 2200 LT; second, the wind directions across the rotor layer, as measured by the lidars, must consistently record southerly inflow throughout the evening; third, the measured hub-height wind speeds must exceed the turbine cut-in speed; fourth, no major synoptic-scale system should influence the local weather in Iowa throughout the period. On this evening, wind directions at the surface, $850-\mathrm{hPa}$ level, and 500-hPa level were primarily southerly, southwesterly, and westerly, respectively. Throughout the campaign, southerly evening inflow was also recorded on two other evenings, 16 and 23 July 2011. However, the WC2 lidar did not record sufficient data during the evening of 16 July (Mirocha et al. 2015), and the evening transition on 23 July was ambiguous due to afternoon precipitation. Therefore those two cases are not considered.

\subsection{WRF Model Configurations}

We use the Advanced Research WRF model (version 3.6.1) (Skamarock and Klemp 2008) to simulate the wake characteristics on a wind-farm scale during the evening transition. 


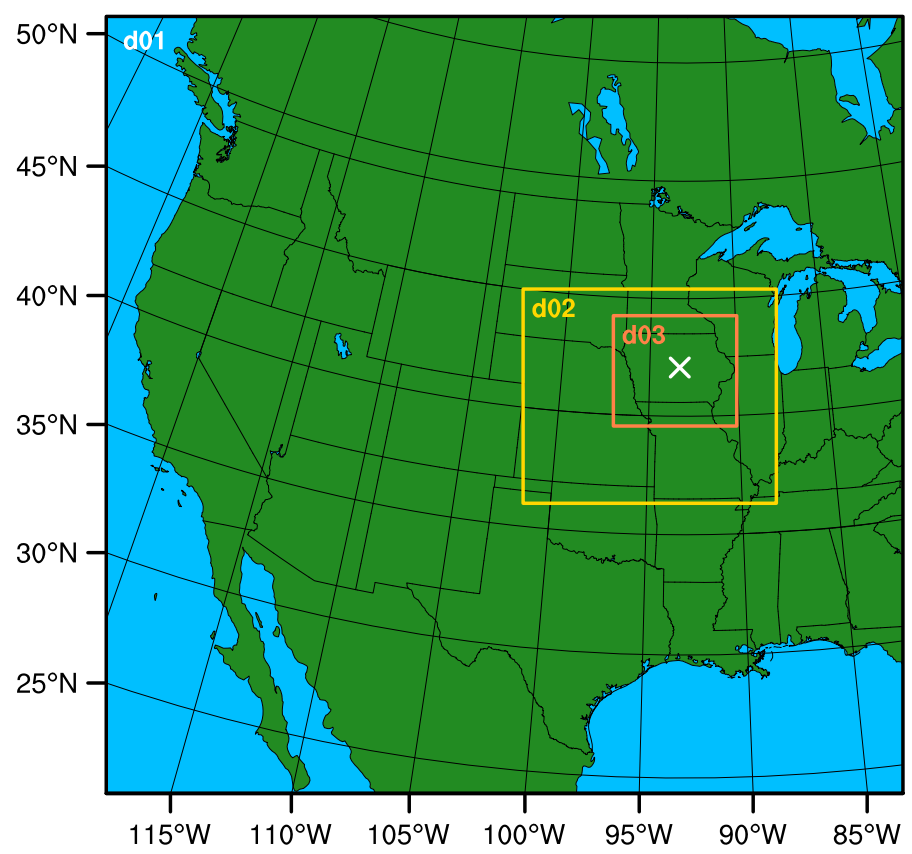

Fig. 2 Map of the three domains simulated with the WRF model: largest grid as d01, intermediate grid as $\mathrm{d} 02$ (yellow) and finest grid as $\mathrm{d} 03$ (orange). The white cross marks the location of the CWEX-11wind farm

To ensure the mesoscale model depicts the upwind conditions correctly, simulation results are compared to the upwind observations before introducing the virtual wind farm. The simulations began at 0000 UTC on 9 July 2011 and ran for $30 \mathrm{~h}$, and we focus on the model data during the evening transition, from 2000 UTC 9 July to 0300 UTC 10 July (1500 to 2200 LT 9 July). The Global Forecast System (GFS) reanalysis provides initial and boundary conditions for the one-way-nested three-domain simulations (Fig. 2). We also tested other initial- and boundary-condition datasets, the ERA-interim dataset and the GFS 0.5-deg resolution dataset. The WRF-model results using the GFS reanalysis data with 1-deg resolution are selected because the wind field, turbulence and surface sensible heat flux are more accurately modelled when forced with the GFS 1-deg resolution dataset (not shown). The finest domain, simulated with $571 \times 511$ points at 990 -m horizontal resolution, covers the entire state of Iowa with an integration timestep of $1 \mathrm{~s}$. To capture the southerly surface flow and the westerly synoptic flow above the surface layer, the inner grids are located northeast of each coarser grid's centre, thus ensuring adequate upwind coverage. To simulate high-resolution boundary-layer features, vertical levels are progressively stretched from the surface, with 70 levels in total. The vertical spacing below $200 \mathrm{~m}$ a.g.l. is about $22 \mathrm{~m}$ on average, allowing for four vertical levels in the rotor layer, nominally at 45, 67, 89, 112, 134, 156, 179 and $201 \mathrm{~m}$ a.g.l.

The Mellor-Yamada-Nakanishi-Niino (MYNN) PBL scheme is currently required for the WRF model to simulate the effects of wind farms via its WFP scheme (Fitch et al. 2012); the MYNN level-2.5 scheme predicts subgrid TKE as a prognostic variable and produces local vertical mixing (Nakanishi and Niino 2006). Based on the Mellor-Yamada-Janjić scheme, the MYNN scheme uses fundamental closure constants derived from LES, and includes stability effects on the mixing length and buoyancy effects on pressure covariance (Nakanishi and 
Niino 2006). The MYNN surface layer and TKE advection in the PBL scheme are also applied. Microphysics is parametrized with the single-moment 3-class scheme (Hong et al. 2004) in the model runs; longwave radiation is estimated with the Rapid Radiative Transfer Model (Mlawer et al. 1997); and the Dudhia scheme provides shortwave radiation (Dudhia 1989). The simulations also use the unified Noah land-surface model, and for the cumulus parametrization, the Kain-Fritsch scheme (Kain 2004) is enabled on the coarsest domain. The non-hydrostatic simulations allow simple diffusion with horizontal Smagorinsky first-order closure and an implicit gravity-wave damping layer.

Of the two sets of simulations, one actively employs the WFP scheme (the "WFP" run) and one has the WFP scheme inactive (the "control" run). In the simulations that included the wind-farm effects, virtual wind turbines are added to the finest domain via the WFP scheme. This scheme explicitly models the elevated drag and turbulent mixing of turbines by establishing an elevated momentum sink and a turbulence source (Fitch et al. 2012). We use the configurations of the 1.5-MW PSU generic turbine (Schmitz 2012), similar to the General Electric SLE turbine described above (80-m hub height and 77-m rotor diameter). The standing thrust coefficient chosen is 0.041 . The WFP run includes a 100-turbine wind farm, which comprised half of the turbines at the site of the CWEX-11 campaign to produce the utility-scale turbine-wake effects. Although the whole wind farm in this location consists of 200 turbines, here we focus on the southern half of the wind farm, the location of the meteorological measurements. Note that the size of a 100-turbine wind farm is representative of most wind farms in North America. Comparison between the control simulation and the WFP simulation indicates the progression of downwind horizontal wind-speed deficits, TKE generation, surface heat flux $Q_{H}$ sign changes and power production through the evening transition.

\section{Results}

\subsection{Observations}

\subsubsection{Evening Transition Characterization}

The near-surface region of the PBL undergoes a transition from convective to stable conditions at least $2 \mathrm{~h}$ before sunset (at 2051 LT) on 9 July 2011 (0151 UTC 10 July), with the stability parameter, $z / L$ (where $z$ is height and $L$ is the Obukhov length) changing from negative to positive at 1830 LT (2330 UTC) (Fig. 3a). The value of the surface heat flux $Q_{H}$ changes sign at the same time (Fig. 3b), while the latent heat flux decreases over time (Fig. 3b). The abrupt collapse of the absolute temporal TKE change ( $|\mathrm{d} \bar{e} / \mathrm{d} t|)$ at hub height (Fig. 3c), which signifies the onset of the transition (Nadeau et al. 2011), coincides with the stability change. The above evidence suggests a distinct evening transition before sunset, consistent with the observations of Grimsdell and Angevine (2002). The differences of $z / L$ and heat fluxes between upwind and downwind sites are trivial, so the downwind stability observations are not presented here.

\subsubsection{Wind Speed Deficits and Turbulence Generation}

The stability, heat flux, and temporal TKE changes affect the wake behaviour in the evening, as illustrated in the upwind (Fig. 4a) and downwind (Fig. 4b) lidar wind profiles and the differences between them (Fig. 4c). When the PBL undergoes transition from an unstable 


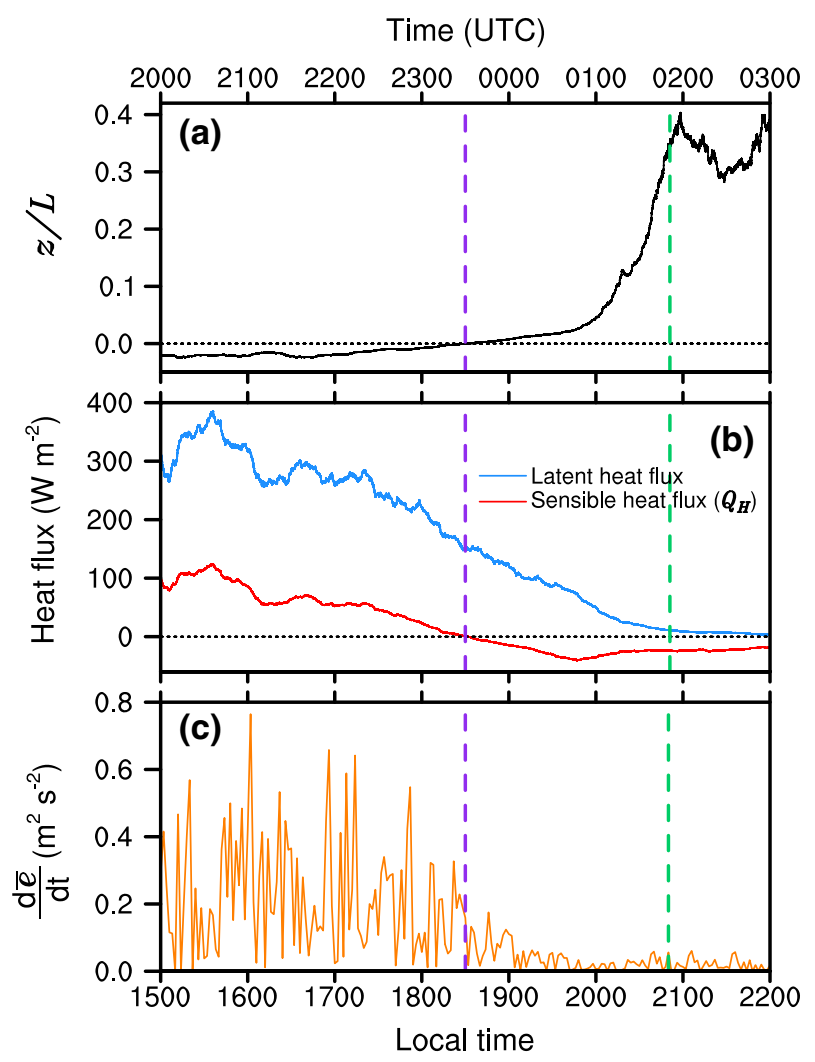

Fig. 3 Time series of stability parameters from the upwind surface-flux station (NCAR1) and lidar (WC1) on 9 July: $z / L(\mathbf{a}), 20-\mathrm{Hz}$ surface sensible and latent heat fluxes (b), and the absolute temporal TKE change at turbine hub height of $80 \mathrm{~m}(|\mathrm{~d} \bar{e} / \mathrm{d} t|)(\mathbf{c})$. The purple vertical dash line indicates the evening transition at 1830 LT (2330 UTC). The green vertical dash line represents the time of sunset at 2051 LT (0151 UTC)

to a stable state, the wake wind-speed deficit is less likely to extend above the height of the rotor top at $118.5 \mathrm{~m}$ (Fig. 4c). Before the transition, convective vertical mixing, initiated by surface heating, leads to relatively uniform upwind wind speeds across the daytime boundary layer (Fig. 4a). When the stable PBL begins to develop, stratification develops in the flow, with lower wind speeds near the surface and greater wind speeds aloft. Stable stratification is initiated at 1900 LT (0000 UTC 10 July), following the evening transition. As the stratification develops, the wind-speed deficit becomes less intermittent over time and is mostly confined to the rotor layer (Fig. 4c).

As with the wind-speed deficit, the turbulence enhancement caused by the wind turbines becomes steady during the evening transition, as evidenced by the upwind $T I$ value (Fig. 5a), upwind $\bar{e}$ value (Fig. 5b), downwind TI value (Fig. 5c), downwind $\bar{e}$ value (Fig. 5d), TI difference (Fig. 5e), and $\bar{e}$ difference (Fig. 5f). From Eqs. 1 and 2, TI represents the variations in horizontal velocities, while the TKE $(\bar{e})$ also accounts for vertical velocity deviations. In the case study, both the upwind $T I$ and $\bar{e}$ values decrease dramatically when the PBL becomes stable (Fig. 5a, b). After the transition, the downwind $T I$ value is confined to the rotor layer (Fig. 5c), although the increase in the $\bar{e}$ value persists above the rotor layer (Fig. 5d). In the wake region, the TKE varies above the rotor layer before and after the evening transition 


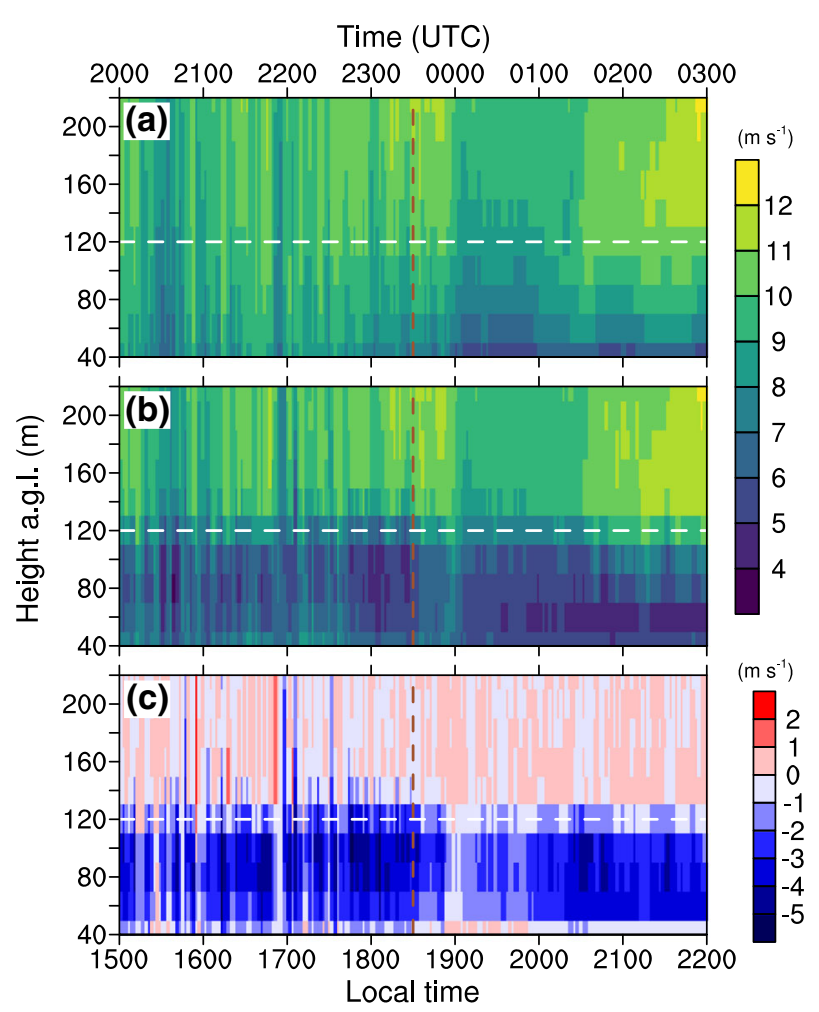

Fig. 4 Time-height contours of 2-min averaged lidar wind-speed measurements on 9 July: upwind measurements from the WC1 lidar (a), downwind measurements from the WC2 lidar (b) and the difference of upwind minus downwind (c). The brown vertical dash line indicates the onset of the evening transition at 1830 LT (2330 UTC). The white horizontal dash line represents the top of the rotor layer, at $118.5 \mathrm{~m}$ a.g.1

(Fig. 5f), while TI values have no substantial differences above the rotor top (Fig. 5e). This contrast between $T I$ and $\bar{e}$ values suggests that vertical velocity variations contribute most to the turbulence enhancement above the turbine rotor layer during the evening transition, consistent with previous wind-tunnel studies (Cal et al. 2010) and idealized LES results (Calaf et al. 2010), which emphasize the importance of the vertical flux stimulated by wakes.

Within the rotor layer, the altitude of the maximum in downwind turbulence enhancement evolves throughout the transition. The height of maximum downwind turbine-induced turbulence generation varies within the rotor layer before 2000 LT (0100 UTC 10 July) and stabilizes at $60 \mathrm{~m}$ afterwards (Fig. 5e). On the other hand, no distinct trends emerge regarding the changes in the height of the peak downwind TKE enhancement (Fig. 5f).

Although upwind turbulence intensity declines during the evening transition, the downwind turbulence enhancements within the rotor layer, due to the turbine, remain at the same order of magnitude throughout the evening transition. Our wake observations, recorded at a distance $3 D$ downwind of turbines, differ from the conclusions of Magnusson and Smedman (1994), where the maximum values in turbulence enhancements diminish downwind more rapidly in unstable than in stable conditions. However, their observations, obtained at a distance $4.2 \mathrm{D}$ downwind, were only relevant to stable and unstable states and not to the transition period. 


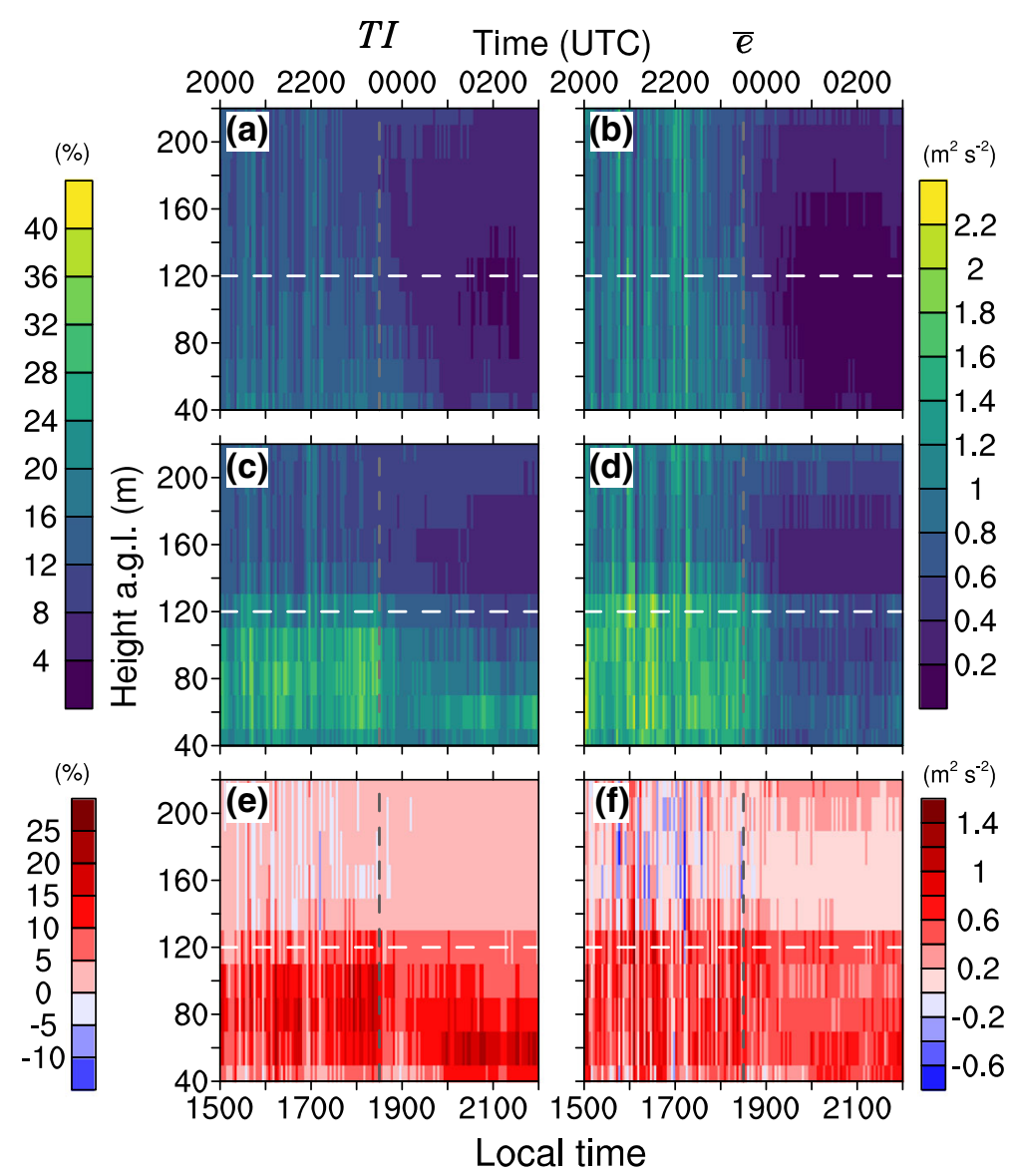

Fig. 5 Time-height contours of 2-min averaged lidar-measured TI and $\bar{e}$ values on 9 July: upwind measurements from the WC1 lidar (a, b), downwind measurements from the WC2 lidar (c, $\mathbf{d})$ and the difference of upwind minus downwind $(\mathbf{e}, \mathbf{f})$. The grey vertical dash line indicates the onset of the evening transition at 1830 LT (2330 UTC). The white horizontal dash line represents the top of the rotor layer, at $118.5 \mathrm{~m}$ a.g.1

\subsubsection{Wake Evolution with Heights and Wind Directions}

Not surprisingly, wake features in the evening transition respond to subtle variations in the upwind wind profiles. The fluctuations of upwind variables decrease gradually during the transition, with the upwind hub-height wind speed oscillating around $8 \mathrm{~m} \mathrm{~s}^{-1}$ and fluctuating less frequently after 1900 LT (0000 UTC 10 July) (Fig. 6a). At the same time, the background $T I$ and $\bar{e}$ values at hub height also begin to decline steadily (Fig. 6b, c). As the inflow becomes steady after the evening transition, the wake signatures in wind speed, TI and TKE are only observed below the rotor top. In contrast, before the evening transition, these wake signatures appear occasionally above the rotor top (Fig. 6d-f). All three wake parameters vary collectively below hub height after 2030 LT (0130 UTC 10 July). Overall, the maximum wake effects steadily become more distinct within the rotor layer as the evening progresses.

This sensitivity of the height of the maximum downwind wind-speed deficit to atmospheric stability has yet to be examined in the literature. Aitken et al. (2014a) summarized the dis- 


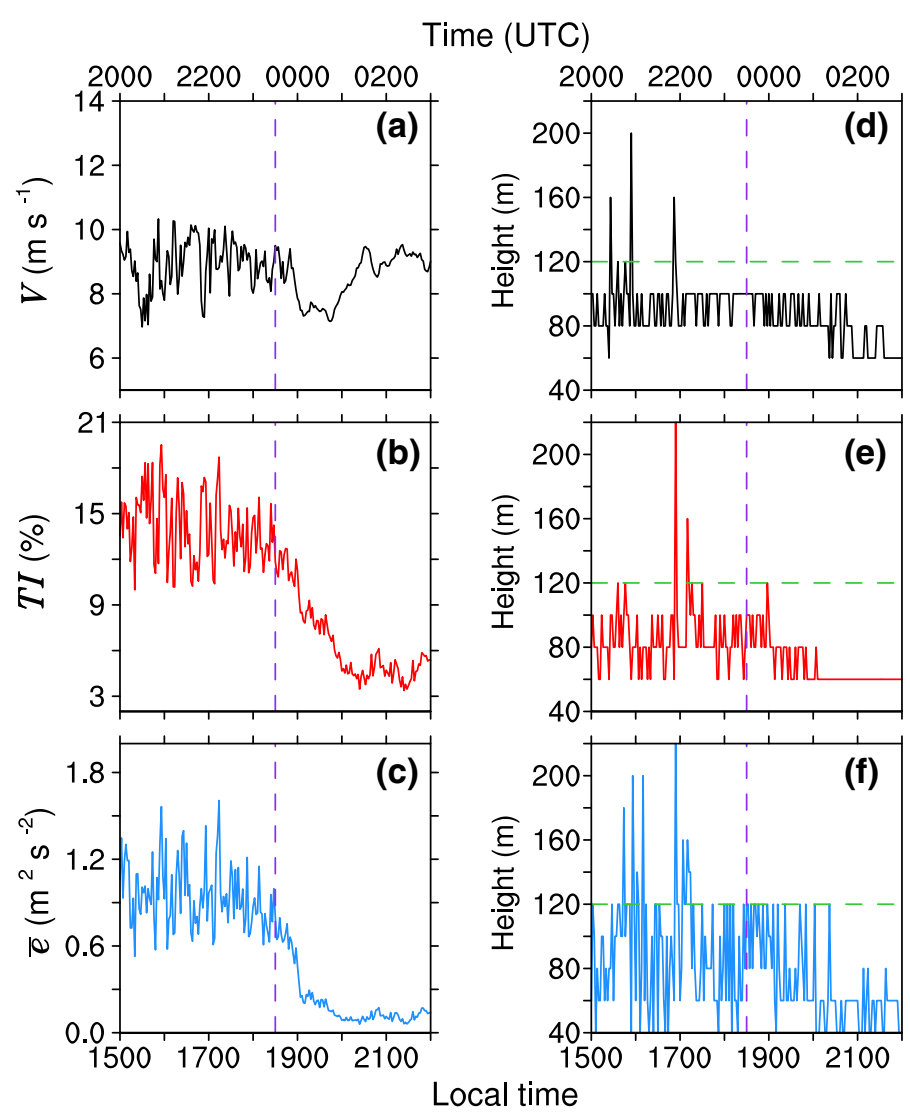

Fig. 6 Left column presents the time series of 2-min averaged measurements from the WC1 lidar at $80 \mathrm{~m}$ a.g.1. on 9 July: wind speed $V$ in black (a), TI values in red (b) and $\bar{e}$ values in blue (c). Right column presents the altitude evolution of the absolute maximum differences between upwind and downwind lidar measurements in wind speed (d), TI (e) and $\bar{e}(\mathbf{f})$. The purple vertical dash line indicates the onset of the evening transition at 1830 LT (2330 UTC). The green horizontal dash line represents the top of the rotor layer, at $118.5 \mathrm{~m}$ a.g.1

crepancy on the altitudes of peak wind-speed deficit among previous investigations, although the role of atmospheric stability was not discussed, since stability was not always quantified in the historical observational studies. Using LES, Bhaganagar and Debnath (2015) characterized wind-speed deficit in two stable scenarios with different surface cooling rates. They concluded that in strongly stable atmospheric conditions, the maximum downwind deficit was found below hub height, while in weakly stable atmospheric conditions, the maximum downwind deficit developed above hub height. The contrast of wakes in different atmospheric stabilities was, nonetheless, not discussed. Abkar and Porté-Agel (2015) hypothesized that the maximum wind-speed deficit occurred at hub height regardless of atmospheric stability, though we have found different results in this case study: the height of maximum wind-speed deficit changes over time as the atmosphere evolves from unstable to stable stratification.

In addition to the change in altitude of the maximum wake wind-speed deficit, the wake also becomes more sensitive to upwind wind direction during the evening transition, likely due to the smaller effect of ambient turbulence on the wake. Upwind wind direction influences the wake parameters across the rotor layer. Additionally, veering, or clockwise turning with 


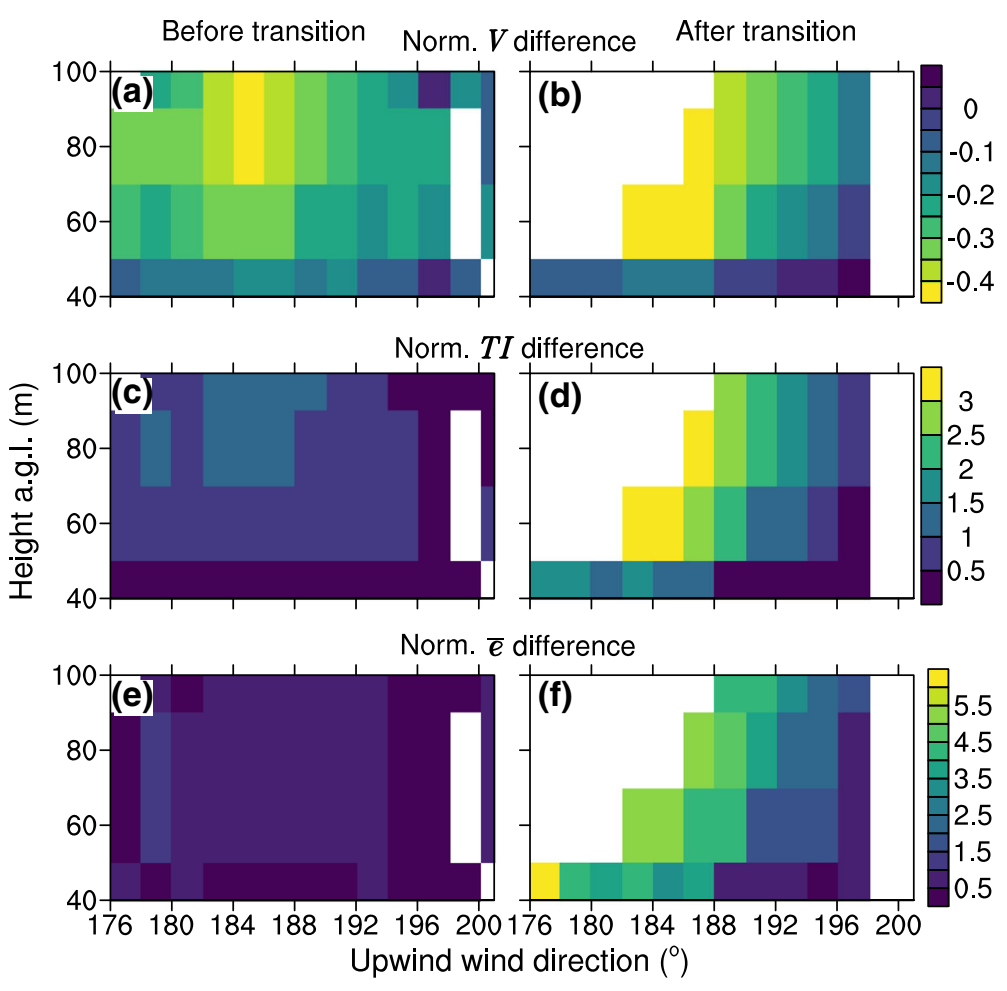

Fig. 7 Contour plots of normalized differences between upwind and downwind lidar measurements in wind speed $(\mathbf{a}, \mathbf{b}), T I(\mathbf{c}, \mathbf{d})$ and $\bar{e}(\mathbf{e}, \mathbf{f})$ as a function of upwind wind direction at heights across the rotor layer, from 40 to $100 \mathrm{~m}$ a.g.l. Left column (a, c, e) illustrates the normalized differences before the evening transition, from 1500 to 1830 LT (2000 to 2330 UTC). Right column (b, d, f) displays the wake effects after the evening transition, from 1830 to 2200 LT (2330 to 0300 UTC 10 July). The normalized differences are averaged in 2-deg wind-direction bins

height in the wind profile, commences during the evening transition; this veering affects the wake. Before the evening transition, southerly inflow ranges from directions $176^{\circ}$ to $200^{\circ}$ and produces the strongest normalized downwind wind-speed deficit centred at $185^{\circ}$ (Fig. 7a), while the downwind turbulence enhancement is relatively weak in magnitude and thus indistinct (Fig. 7c, e). After the evening transition, both the inflow and the wake start to veer with height. The wind-speed deficit is greatest around $185^{\circ}$, especially below hub height (Fig. 7b). In the same way, the normalized $T I$ and $\bar{e}$ differences demonstrate intensifying wake effects, mainly at and below hub height (Fig. 7d, f). In general, the turbulence enhancements veer with height, and have the greatest values around $185^{\circ}$. Note that Fig. 7 only illustrates data up to $100 \mathrm{~m}$ a.g.l., since the downwind lidar may well sample partial wakes beyond that height. Overall, the wakes veer and become more distinct during the evening transition of 9 July.

\subsection{Observation-Simulation Comparison}

We first evaluate the skill of the WRF model in simulating the evolution of the upwind profiles of wind speed, wind direction, and TKE. Although the maximum absolute error of wind speed 


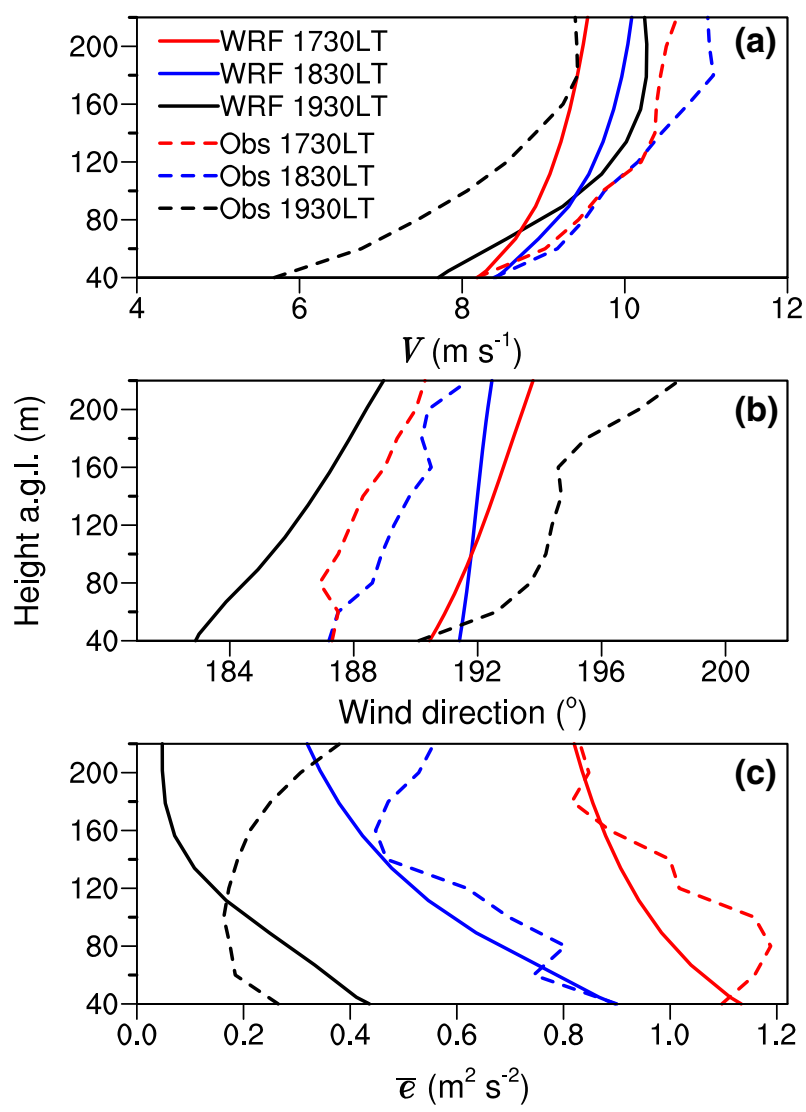

Fig. 8 Vertical profiles from the WC1 lidar (abbreviated as Obs, dash lines) and the WRF-model simulations at the nearest grid point from the WC1 lidar (solid lines) of wind speed (a), wind direction (b), and $\bar{e}$ (c) at three different times, 1730 (red), 1830 (blue) and 1930 (black) LT on 9 July (2230, 2330 and 0030 UTC)

at hub height before, during and after the evening transition is $1.5 \mathrm{~m} \mathrm{~s}^{-1}$, the model captures the temporal trend of the wind-speed profile (Fig. 8a). Even as the error of the wind-direction profile grows over time, the simulation error in the $80-\mathrm{m}$ wind direction is less than $10^{\circ}$ throughout the evening transition (Fig. 8b). Moreover, the simulated TKE profile and its decline in magnitude during the transition generally agree with the observations (Fig. 8c), with a hub-height maximum error in $\bar{e}$ of $0.18 \mathrm{~m}^{2} \mathrm{~s}^{-2}$. Note that the observed TKE is the lidarmeasured, 2-min averaged TKE. The WRF-calculated TKE is a mesoscale representation of atmospheric turbulence over the entire grid cell, and as such is not directly comparable to the observations, but is shown for reference in Figs. 8c, 9c.

Likewise, the comparison between modelled and observed time series further supports the claim that the WRF model is capable of simulating the upwind condition. The mean absolute errors between the simulated and observed time series of hub-height wind speed, hub-height wind direction, hub-height TKE $(\bar{e})$ and surface heat flux $Q_{H}$ on 9 July are small, being $1.1 \mathrm{~m} \mathrm{~s}^{-1}, 7.7^{\circ}, 0.17 \mathrm{~m}^{2} \mathrm{~s}^{-2}$ and $21 \mathrm{~W} \mathrm{~m}^{-2}$, respectively (Fig. 9). On the other hand, the timing of the simulated atmospheric stability change is within $1 \mathrm{~h}$ of the actual change: $Q_{H}$ changed sign at 1755 LT (2255 UTC) in the WRF model, 35 min earlier than that 


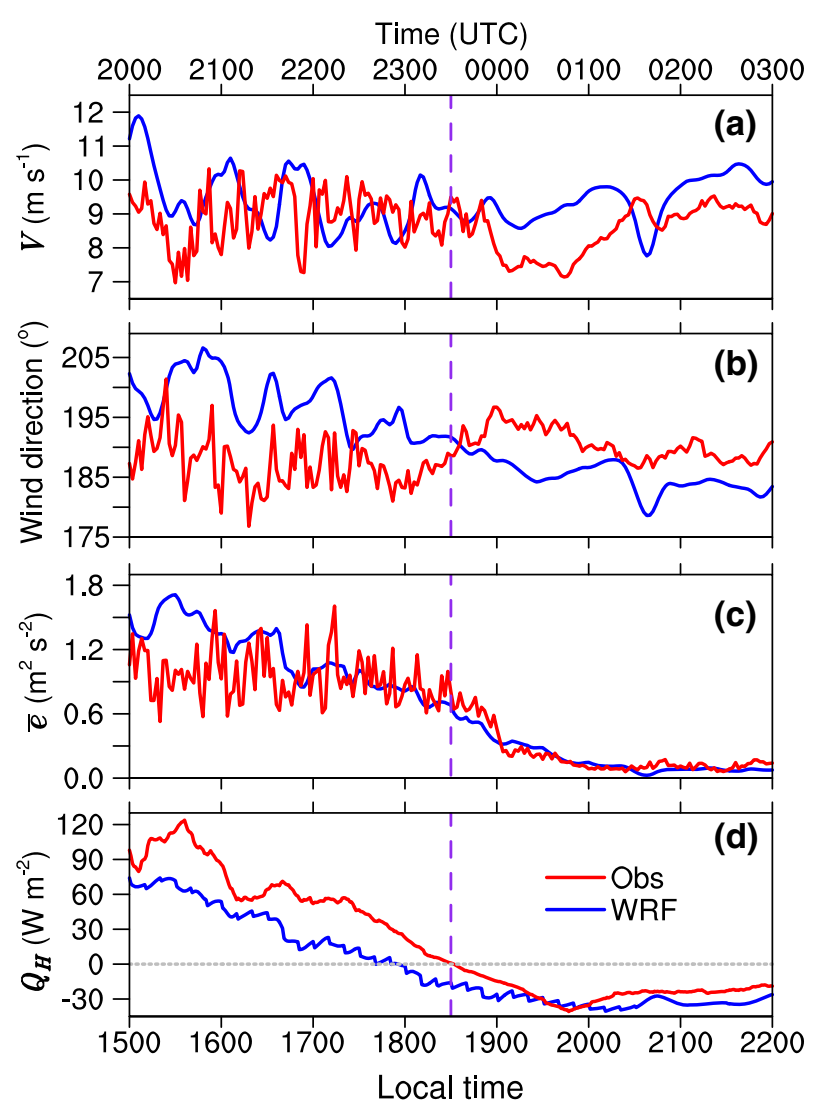

Fig. 9 Time series from the WC1 lidar at $80 \mathrm{~m}$ a.g.l. (red) and the WRF-model simulations at the nearest grid point from the WC1 lidar (blue) on 9 July: 2-min averaged hub-height wind speed (a), 2-min averaged hubheight wind direction (b), 2-min averaged hub-height TKE $(\bar{e})(\mathbf{c})$ and 1-min averaged surface heat flux $Q_{H}$ (d). The WRF-model variables plotted are interpolated to hub height. The purple vertical dash line indicates the onset of the evening transition at 1830 LT (2330 UTC)

observed. However, the simulated hub-height TKE experiences abrupt decay at the same time as that observed, 1900 LT (0000 UTC 10 July) (Fig. 9c). Overall, the WRF model produces satisfactory background flows for this 9 July case study.

\subsection{Simulations with the WFP Scheme}

\subsubsection{Downwind Meteorological Impacts}

Via the WFP scheme, virtual wind turbines are introduced in the 9 July WRF model simulation to characterize the evolution of wake effects during the evening transition. Wind-speed deficit, calculated by subtracting the horizontal wind speed of the "control" run with no virtual wind turbines from that of the "WFP" run with virtual turbines, is the primary method to quantify wind-farm wakes. The modelled wind-speed deficits produced by the 100-turbine wind farm intensify at hub height over time, and extend further downwind after the evening transition at 1830 LT (2330 UTC) (Fig. 10a-d). The wind-speed deficits reach a maximum value within 


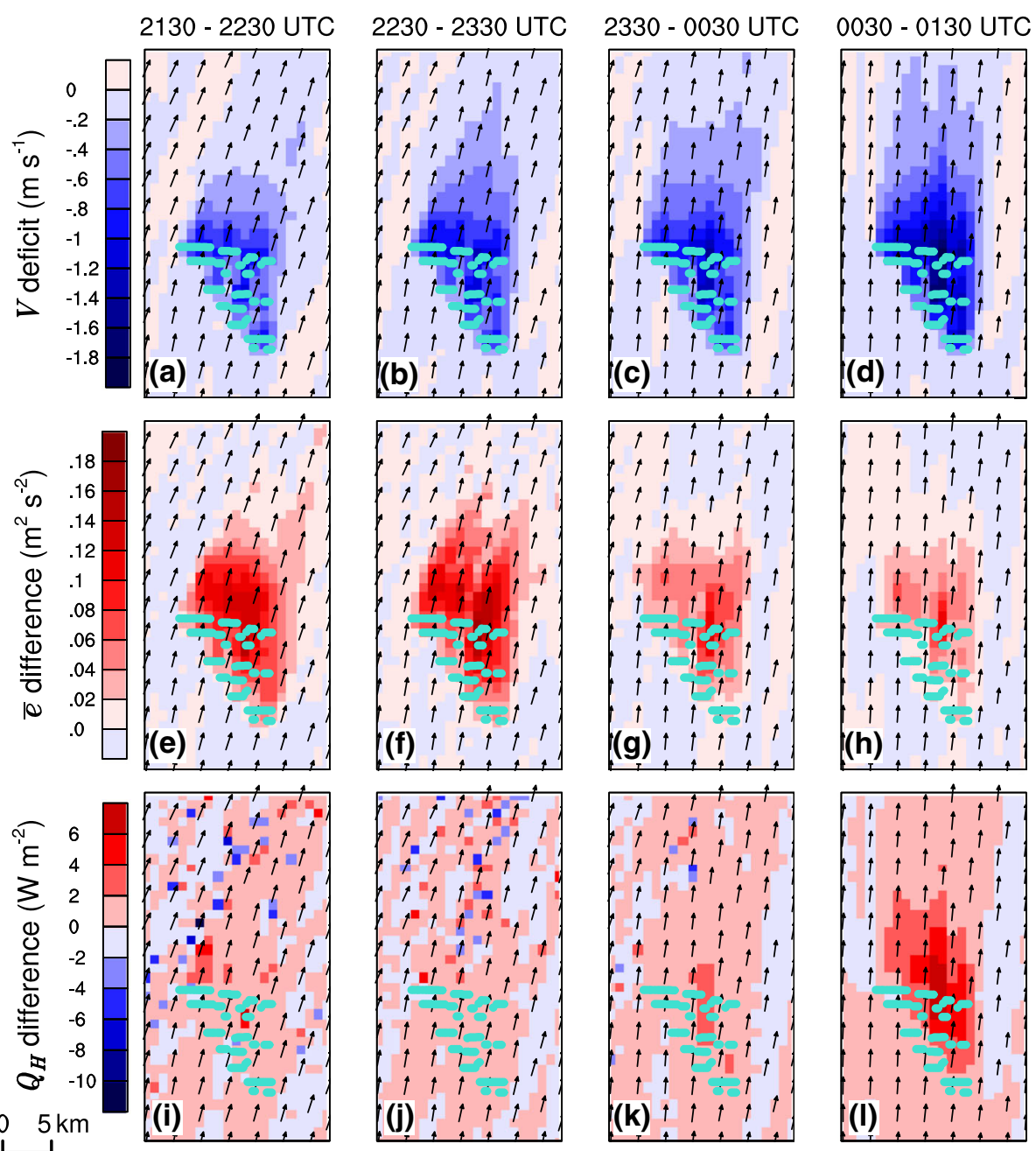

Fig. 10 1-h averaged differences of simulated hub-height wind speed (a-d), hub-height $\bar{e}(\mathbf{e}-\mathbf{h})$ and surface heat flux $Q_{H}(\mathbf{i}-\mathbf{l})$, subtracting the variables of the "control" run from those of the "WFP" run, over $4 \mathrm{~h}$ from 1630 to 2030 LT (2130 to 0130 UTC) 9 July: 2130 to 2230 UTC (a, e, i), 2230 to 2330 UTC (b, f, j), 2330 to $0030 \mathrm{UTC}(\mathbf{c}, \mathbf{g}, \mathbf{k})$, and 0030 to $0130 \mathrm{UTC}(\mathbf{d}, \mathbf{h}, \mathbf{l})$. The black vectors represent the $1-\mathrm{h}$ averaged wind direction of the control run interpolated to hub height, and the vector lengths are proportional to the wind speed of the control run. The turbine locations are labelled as dots in cyan

a distance of $5 \mathrm{~km}$ downwind from the northern edge of the virtual wind farm, and the windspeed deficits erode for distances further downwind. As the simulated wind direction shifts from south-westerly to southerly throughout the transition, the location of the wake windspeed deficits changes accordingly. Additionally, the hub-height wind speed of the control run varies between 8 and $11 \mathrm{~m} \mathrm{~s}^{-1}$ during the $2 \mathrm{~h}$ before and after the evening transition (Fig. 9a). The wind-farm drag reduces the downwind wind speed by more than $1.2 \mathrm{~m} \mathrm{~s}^{-1}$ throughout the transition; this wind-farm wake represents more than $10 \%$ of the inflow wind speed at the end of the transition (Fig. 10d). 


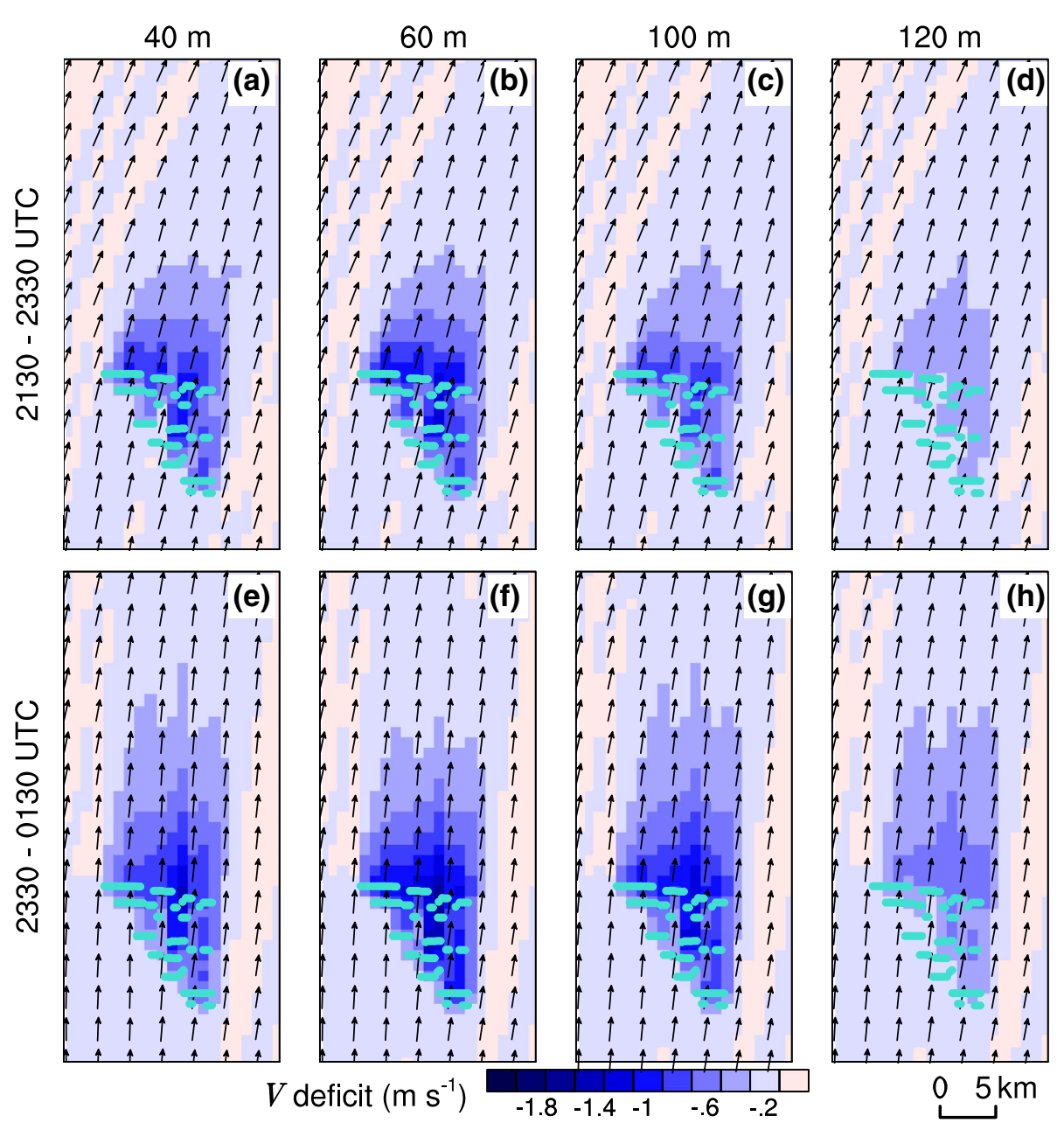

Fig. 11 2-h averaged WRF-model wind-speed difference, subtracting wind speed of the control run from wind speed of the WFP run from 1630 to 1830 LT 9 July (2130 to 2330 UTC) (a-d) and from 1830 to 2030 LT 9 July (2330 to 0130 UTC) $(\mathbf{e}-\mathbf{h})$ at $40(\mathbf{a}, \mathbf{e}), 60(\mathbf{b}, \mathbf{f}), 100(\mathbf{c}, \mathbf{g})$ and $120(\mathbf{d}, \mathbf{h}) \mathrm{m}$ a.g.l. As in Fig. 10, the vectors represent the wind field of the control run and the cyan dots represent the wind-turbine locations

The simulated wind-speed deficit within the rotor layer also becomes greater during the evening transition. Throughout the evening transition, the wind-speed deficit is greater below hub height than above (Fig. 11). At the top of the rotor disk, the wind-speed reduction is minimal before the evening transition, but doubles after the transition (Fig. 11d, h). At all altitudes across the rotor disk, the wind-speed deficits stretch further downwind after the transition than before the transition.

Although the absolute changes in hub-height TKE difference decrease over time (Fig. 10eh), the virtual wind turbines increase the relative downwind TKE difference during the evening transition. Since the background TKE diminishes as the evening progresses (Fig. 9c), the TKE enhancement produced by the wind farm decreases in absolute terms but increases in relative terms. One hour before the evening transition, the turbines generate a maximum downwind TKE enhancement of more than $0.18 \mathrm{~m}^{2} \mathrm{~s}^{-2}$ (Fig. 10f), which is about $20 \%$ of 


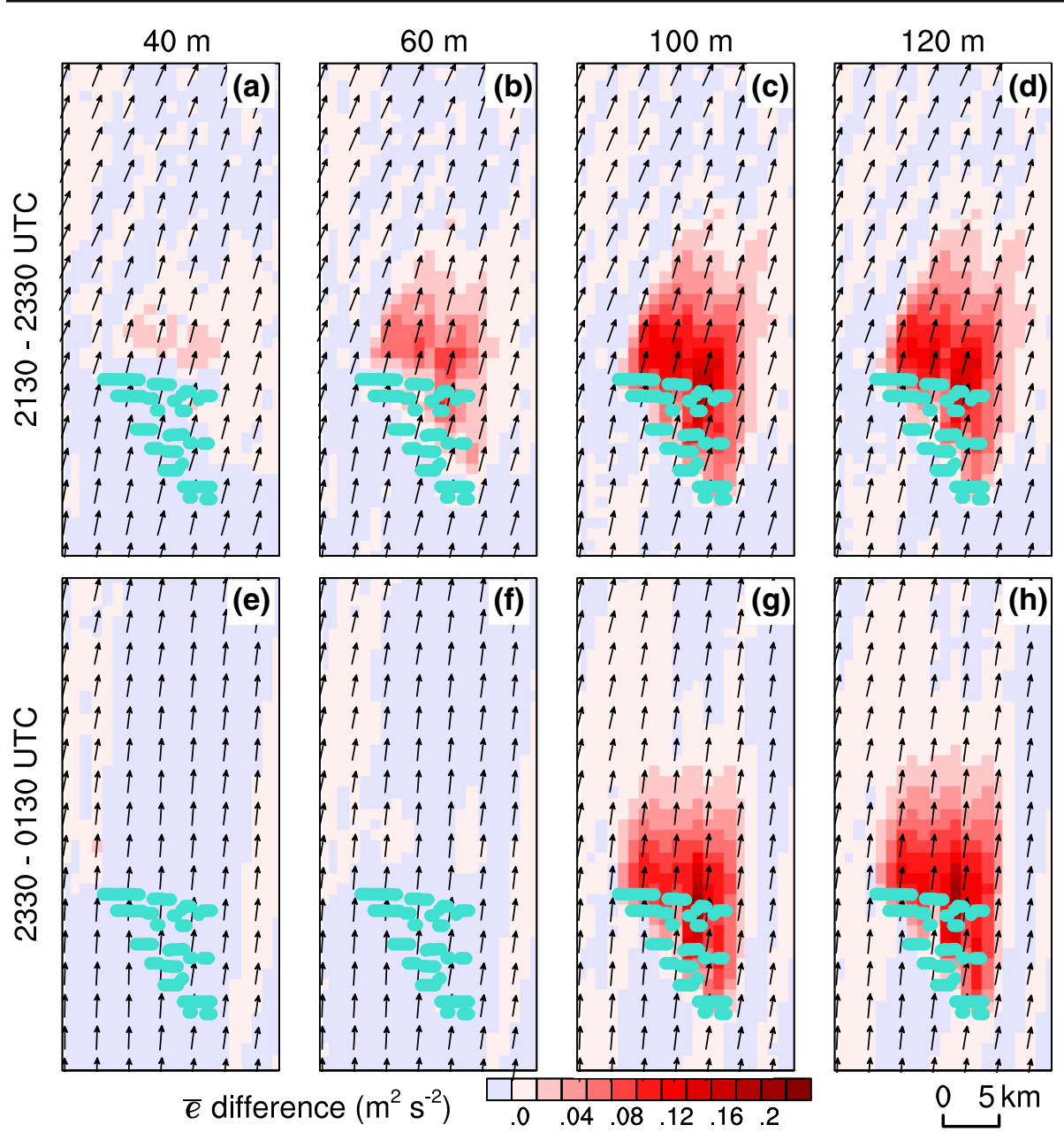

Fig. 12 As in Fig. 11, the variable shown is 2-h averaged TKE $(\bar{e})$ difference across the rotor layer

the average ambient TKE value of the hour in the control run (Fig. 9c). By the end of the transition, the downwind TKE enhancement is more than $50 \%$ of its base value (Fig. 10h): the downwind TKE increases by $50 \%$ due to the existence of the wind farm.

Furthermore, the downwind TKE differences across the rotor layer display irregular variations, in contrast to the wind-speed deficits. In general, the downwind TKE enhancement increases with height within the rotor layer throughout the evening transition (Fig. 12). Particularly below hub height, the TKE enhancement induced by the virtual wind farm diminishes after the transition (Fig. 12e, f). On the other hand, above hub height, the differences in TKE enhancement before and after the transition are more subtle (Fig. 12c, d, g, h). Furthermore, in terms of horizontal extent, the downwind wind-speed deficit at hub height persists for a distance of more than $15 \mathrm{~km}$ downwind after the evening transition (Fig. 10c, d), but the TKE enhancement dissipates after a distance of $10 \mathrm{~km}$ downwind (Fig. 10g, h).

Besides, wind turbines also interrupt the evening reduction of the surface heat flux $Q_{H}$ downwind, as well as the emergence of the near-surface stable layer. At the beginning of the 
evening transition, the virtual wind farm increases $Q_{H}$ by less than $2 \mathrm{~W} \mathrm{~m}^{-2}$ consistently (Fig. 10i), which is less than $10 \%$ of the control value (Fig. 9d). As the evening progresses, the wind farm enhances and expands the downwind flux increase by more than $6 \mathrm{~W} \mathrm{~m}^{-2}$ at the end of the transition (Fig. 101), which is about $20 \%$ of the ambient value (Fig. 9d). In contrast, $Q_{H}$ in a typical environment should decrease and become negative in the evening. Therefore, the positive downwind heat-flux difference during the evening transition suggests the modelled wind turbines impede downwind surface cooling and hence the development of the nocturnal stable boundary layer.

\subsubsection{Power Production Evolution}

In the "WFP" simulations, turbine-power production can be calculated from the wind speed at hub height in a simulation cell. The power ratio (Fig. 13) represents the ratio between the WFP-simulated power production and the calculated power production derived from the wind speeds of the same turbine-containing grid cells in the "control" run, based on the turbine power curve. As expected, waked grid cells produce less power. Because the wind direction shifts from south-south-westerly to southerly, the grid cells on the south-western half of the wind farm consistently yield higher power per turbine than those in the north-eastern half, which are usually waked. Note that the WFP scheme assumes that the virtual wind turbines are always oriented perpendicular to the flow (Fitch et al. 2012), and the power production of each grid cell is proportional to the number of turbines contained therein.

Because of the strengthening wakes during the 4-h evening transition, the 1-h averaged power ratio gradually decreases to $68 \%$, from $82 \%$ (Fig. 13). The reduction in the power ratio during the first $2 \mathrm{~h}$ can be explained by the larger decline in the average wind speed of the WFP run compared to that of the control run (Fig. 14). Meanwhile, the mean power ratio continues to decrease even when the wind speeds increase after 1900 LT (0000 UTC 10 July) (Fig. 14), indicating a growing discrepancy between the potential and the WFP-simulated power productions throughout the evening transition. The continuous reduction in power ratio (Figs. 13, 14) illustrates that the maturing wakes undermine the power production of downwind turbines.

\section{Discussion}

Because daily electricity demand increases during the evening, efforts to provide reliable electricity generation from wind energy must include a characterization of wind-turbinewake behaviour during the evening transition. Here, we have investigated the evolution of wind-turbine wakes using both observations and model simulations of a case study when the lower PBL undergoes a transition from typical daytime convective to nocturnal stable conditions.

Turbine wakes undermine power production of downwind turbines. Wake characteristics, such as downwind wind-speed deficits and downwind turbulence generation, respond to the decoupling of the surface layer from the PBL during the evening transition. In the evening, the sign of the heat flux $Q_{H}$ becomes negative as the ground starts to cool, the atmospheric PBL develops stable stratification, and the background wind direction veers with height and undergoes transition into a laminar flow. During the evening transition, variable daytime turbine wakes coalesce and appear to be more persistent and more confined within the rotor disk altitudes. 

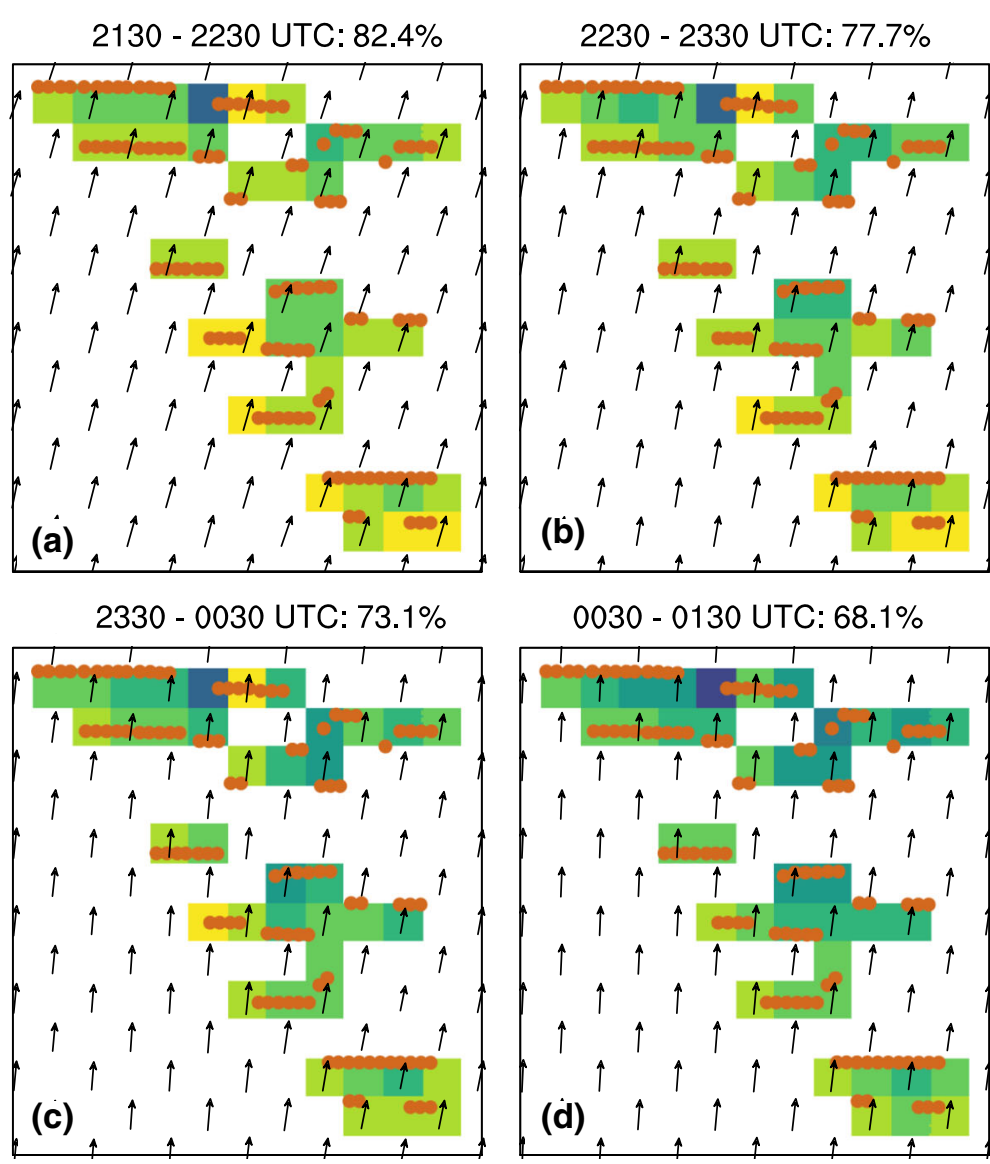

0030 - 0130 UTC: $68.1 \%$

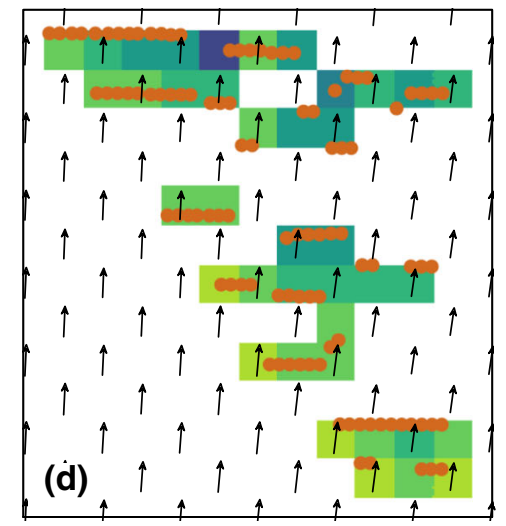

Power ratio (\%)

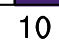

30

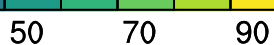

Fig. 13 1-h averaged power ratio in each grid cell over $4 \mathrm{~h}$ from 1630 to 2030 LT (2130 to 0130 UTC) 9 July: 2130 to $2230 \mathrm{UTC}$ (a), 2230 to $2330 \mathrm{UTC}$ (b), 2330 to $0030 \mathrm{UTC}$ (c), and 0030 to $0130 \mathrm{UTC}$ (d). The black vectors represent the $1-\mathrm{h}$ averaged wind speeds of the WFP run, and vector lengths are proportional to the wind speed. The brown dots represent the turbine locations. The numbers following the time periods represent the 1 -h averaged power ratio of the 100 turbines

The evolving upwind profile and the declining convective turbulence in the evening also determine the height of the strongest wakes within the rotor layer. In an unstable regime, the largest wind-speed deficit is observed above hub height. After the evening transition, the maximum in the wind-speed deficit is found below hub height (Fig. 6a). The heights of the maximum wind-speed deficit and turbulence production also coincide, especially after the evening transition, due to the strengthening atmospheric stratification (Fig. 6). The wakes themselves begin to veer with height across the rotor layer after the evening transition (Fig. 7). Previous studies (Aitken et al. 2014a; Bhaganagar and Debnath 2015; Abkar and Porté-Agel 2015) did not examine the effects of atmospheric stratification on the height of the maximum wind-speed deficit in the wake, and our study has demonstrated the strong influence of evolving stability on the height of the maximum wake. Empirical reduced-order 


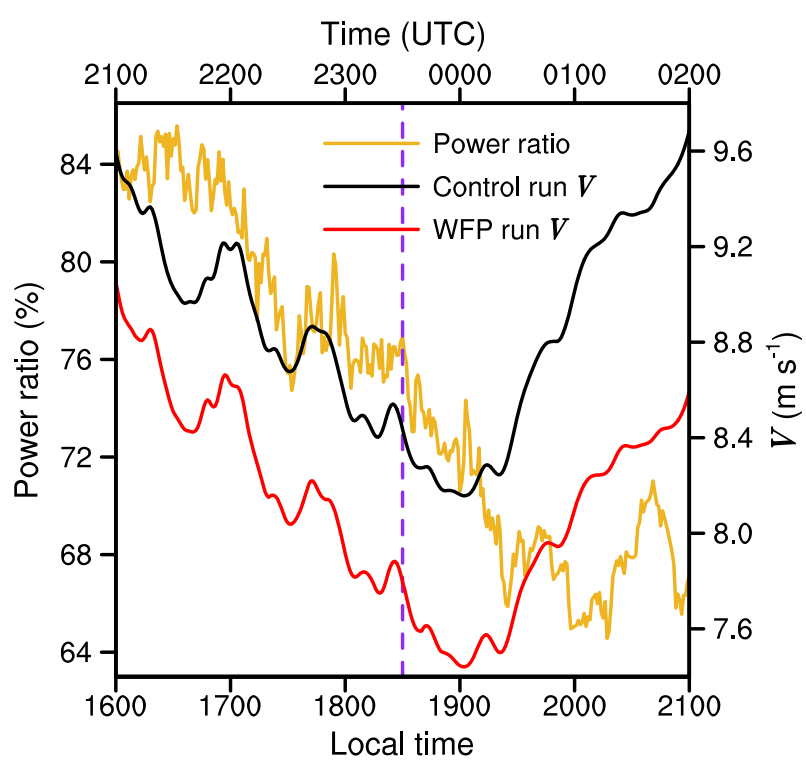

Fig. 14 Time series of the power ratio (yellow), the average control-run wind speed (black) and the average wind speed of the WFP run at hub height (red) among all turbine-containing grid cells, from 1600 to 2100 LT 9 July (2100 UTC to 0200 UTC 10 July). The purple vertical dashed line indicates the onset of the evening transition at $1830 \mathrm{LT}$ (2330 UTC)

wake models (Jensen 1983; Katíc et al. 1986) could therefore be modified to account for evolving stability.

Introducing a virtual wind farm into the WRF-model simulations enables the exploration of wind-farm-wake behaviour during the evening transition. The maximum hub-height windspeed deficit and turbulence enhancement take place within $5 \mathrm{~km}$ of the downwind edge of the wind farm (Fig. 10a-h), which is consistent with the WRF-model simulations of Fitch et al. (2013a) and Jiménez et al. (2015). Moreover, after the evening transition, the hub-height wind-speed deficit persists for more than $15 \mathrm{~km}$ downwind, while the turbulence enhancement vanishes beyond $10 \mathrm{~km}$ downwind. In contrast to LES studies with constant atmospheric stratification (Churchfield et al. 2012; Mirocha et al. 2014, 2015; Abkar and Porté-Agel 2015; Vanderwende et al. 2016a), the wake structure illustrated herein varies both temporally and spatially downwind of the wind farm. The turbine locations in these simulations, based on an actual wind farm, contribute to this variability. Furthermore, the left-hand-side downwind horizontal flow acceleration or turning during the evening transition found in Fitch et al. (2013a) does not emerge in the simulations presented herein. Nonetheless, we observe a strengthening of the downwind wind-speed deficit throughout the evening transition, similar to that of Fitch et al. (2013a). The validity of the power production from the WFP scheme awaits verification from observations.

The wake behaviour in the individual wake observations is different from that in the windfarm wake simulations, and the results herein of wake evolution through the evening transition may serve as reference for improving the WFP scheme in the WRF model. Of course, differences between simulations and observations may be due to scale, as our observations are within one mesoscale model cell, and variability within the cell is not permitted using the current WFP scheme. Simulations suggest that after the evening transition, the modelled wind-speed deficit strengthens more near hub height than at the top and bottom of the rotor 
layer (Figs. 10c, d, 11), which agrees with the observations (Fig. 7b). However, the WFP scheme underestimates the maximum wind-speed deficit at and above hub height by about $1 \mathrm{~m} \mathrm{~s}^{-1}$ (not shown). In addition, the observed maximum TKE enhancement within the rotor layer (Fig. 5f) is also at least twice as large as the modelled downwind $\bar{e}$ increase in the evening (Figs. 10e-h, 12). Considering the wind-speed deficit and TKE enhancement decrease with downwind distance, these observation-model differences may be due to the resolution of the mesoscale model as compared to the observations. After all, the observations are collected at a location about $240 \mathrm{~m}$ downwind, while the simulations are representative of a $1 \mathrm{~km} \times 1 \mathrm{~km}$ grid cell. Moreover, the elevation of TKE enhancement also differs between measurements and simulations: after the evening transition, the simulated downwind TKE increase only occurs above hub height (Fig. 12e-h), conversely, the observed TKE increase downwind across the rotor layer (Figs. 5f, 6f). Recognizing that the observations and the WFP scheme depict turbine wakes at different spatial scales, the parametrization still has difficulties describing evening wake evolution, particularly TKE enhancement below hub height. The observation-simulation disagreement in wake behaviour is due to a combination of measurement errors, differences in observed and simulated upwind conditions, and the fundamental limitation of the WFP scheme in characterizing sub-grid features. In the CWEX11 simulations, some grid cells contain multiple turbines, and the WFP scheme cannot model sub-grid scale phenomena, contributing to the observation-simulation differences.

During the evening transition, power production decreases in the wind-farm simulations, due both to strengthening wakes and the temporal and spatial variability of the inflow to the turbines. Accompanying the small fluctuations in the simulated hub-height wind direction of less than $20^{\circ}$ (Fig. 9b), the background wind speed oscillates between 8 and $11 \mathrm{~m} \mathrm{~s}^{-1}$ and remains below rated speed during the evening transition (Fig. 9a). The freestream wind speed is in region II of the turbine power curve, where the power production is highly sensitive to wind-speed variations. Before the evening transition, the temporal trend of power generation in the turbine-containing grid cells follows closely the upwind wind-speed changes, which explains the rapid reduction of the power ratio during the evening transition (Figs. 13, 14). After the evening transition, stronger wakes lead to a lower downwind power ratio, so the average power production continues to plummet even as the wind speed rebounds. The modelled streaks of gusts or lower wind speeds across the whole wind farm also produce fluctuations in the overall power production. The stability transition near the surface modifies the wind-profile stratification; this progression can also lead to reductions in power output during the evening transition.

\section{Conclusions}

Herein, we present the evolution of both observed and simulated wind turbine wakes during the evening transition. Through the evening transition, the vertical extent of the wake wind-speed deficit, produced by an individual turbine, gradually decreases and becomes confined within the rotor layer. After the upwind buoyancy-driven turbulence diminishes in the evening, the downwind turbulence generation rebounds and persists within the rotor layer. Transitioning surface inflow and strengthening wakes introduce temporal fluctuations in downwind power deficit.

The mesoscale WRF-model simulations using the WFP scheme also offer a basis for the prediction of power production when the daily electricity demand increases in the evening. As the evening transition progresses, the downwind turbines and the downwind atmosphere 
experience continuously strengthening wake effects. Compared to the control simulations with no wind-turbine effects, the virtual wind farm leads to an increase in hub-height windspeed deficit by more than $10 \%$, a $50 \%$ increase of TKE at hub height, and a $20 \%$ increase in the surface heat flux $Q_{H}$, which stalls surface cooling through the end of the evening transition. The power ratio, a measure of the simulated power generation to the potential power production given undisturbed inflow, decreases nearly $15 \%$ during the transition. Overall, turbine wakes respond to the evolving PBL during the evening transition, thereby affecting total wind-farm power production by reducing the productivity of downwind turbines. As wind-energy control research moves from a focus on manipulating individual turbines to optimizing power production of larger plants (Fleming et al. 2014, 2016), these varying stability-driven wake characteristics should be incorporated into control schemes.

Having demonstrated that the WRF model has skill in simulating the ambient wind field for the selected evening transition case, we demonstrate that the WFP scheme is capable of modelling turbine wakes through changing atmospheric stability conditions. Thus, this study lays the groundwork for future investigations to compare the power output of the WFP scheme to the observed power production, which can be conducted with nacelle anemometer measurements (St. Martin et al. 2017). Since mesoscale modelling is crucial in predicting power production in wind farms (Marquis et al. 2011; Jiménez et al. 2015; Wilczak et al. 2015), comparisons of predicted and observed power output can help to identify areas for improvement in the WFP scheme in the WRF model. Moreover, accurate representation of wind farms in numerical weather prediction models is important for both simulating windenergy production and planning for energy infrastructure (Jacobson et al. 2015; MacDonald et al. 2016).

Acknowledgements The authors gratefully acknowledge the support of the Institute of Geophysics, Planetary Physics and Signatures (IGPPS) at Los Alamos National Laboratory under subcontract 258995 and our colleagues and collaborators at LANL, Rod Linn and Domingo Muñoz-Esparza. The authors thank Dr. Sven Schmitz and his research group at the Pennsylvania State University for the turbine configurations of the PSU Generic 1.5-MW turbine. The authors also thank the NCAR and Iowa State University teams for their efforts in collecting the surface flux data, and thank the reviewers for their valuable comments. This work utilized the Janus supercomputer, which is supported by the National Science Foundation (award number CNS-0821794) and the University of Colorado Boulder. The Janus supercomputer is a joint effort of the University of Colorado Boulder, the University of Colorado Denver and the National Center for Atmospheric Research. Partial support for this research was provided by the National Science Foundation under Grant BCS-1413980 (Coupled Human Natural Systems). The data presented in this study are available in the University of Colorado PetaLibrary (provided by NSF-MRI Grant ACI-1126839).

Open Access This article is distributed under the terms of the Creative Commons Attribution 4.0 International License (http://creativecommons.org/licenses/by/4.0/), which permits unrestricted use, distribution, and reproduction in any medium, provided you give appropriate credit to the original author(s) and the source, provide a link to the Creative Commons license, and indicate if changes were made.

\section{References}

Abkar M, Porté-Agel F (2015) Influence of atmospheric stability on wind-turbine wakes: a large-eddy simulation study. Phys Fluids 27:035104. doi:10.1063/1.4913695

Acevedo OC, Fitzjarrald DR (2001) The early evening surface-layer transition: temporal and spatial variability. J Atmos Sci 58:2650-2667. doi:10.1175/1520-0469(2001)0582.0.CO;2

Aitken ML, Banta RM, Pichugina YL, Lundquist JK (2014a) Quantifying wind turbine wake characteristics from scanning remote sensor data. J Atmo Ocean Technol 31:765-787. doi:10.1175/JTECH-D-1300104.1 
Aitken ML, Kosović B, Mirocha JD, Lundquist JK (2014b) Large eddy simulation of wind turbine wake dynamics in the stable boundary layer using the Weather Research and Forecasting Model. J Renew Sustain Energy 6:033137. doi:10.1063/1.4885111

Angevine WM (2007) Transitional, entraining, cloudy, and coastal boundary layers. Acta Geophys 56:2-20. doi: $10.2478 / \mathrm{s} 11600-007-0035-1$

Baidya Roy S (2011) Simulating impacts of wind farms on local hydrometeorology. J Wind Eng Ind Aerodyn 99:491-498. doi:10.1016/j.jweia.2010.12.013

Bhaganagar K, Debnath M (2015) The effects of mean atmospheric forcings of the stable atmospheric boundary layer on wind turbine wake. J Renew Sustain Energy 7:013124. doi:10.1063/1.4907687

Blahak U, Goretzki B, Meis J (2010) A simple parametrisation of drag forces induced by large wind farms for numerical weather prediction models. In: Proceedings European wind energy conference and exhibition, Warsaw, Poland, pp 186-189

Blay-Carreras E, Pardyjak ER, Pino D, Alexander DC, Lohou F, Lothon M (2014) Countergradient heat flux observations during the evening transition period. Atmos Chem Phys 14:9077-9085. doi:10.5194/acp14-9077-2014

Bonin TA, Blumberg WG, Klein PM, Chilson PB (2015) Thermodynamic and turbulence characteristics of the Southern Great Plains nocturnal boundary layer under differing turbulent regimes. Boundary-Layer Meteorol 157:401-420. doi:10.1007/s10546-015-0072-2

Calaf M, Meneveau C, Meyers J (2010) Large eddy simulation study of fully developed wind-turbine array boundary layers. Phys Fluids 22:015110. doi:10.1063/1.3291077

Cal RB, Lebrón J, Castillo L, Kang HS, Meneveau C (2010) Experimental study of the horizontally averaged flow structure in a model wind-turbine array boundary layer. J Renew Sustain Energy 2:013106. doi:10. $1063 / 1.3289735$

Chamorro LP, Porté-Agel F (2009) A wind-tunnel investigation of wind-turbine wakes: boundary-layer turbulence effects. Boundary-Layer Meteorol 132:129-149. doi:10.1007/s10546-009-9380-8

Churchfield M, Lee S, Moriarty P, Martinez LA, Leonardi S, Vijayakumar G, Brasseur JG (2012) A LargeEddy Simulations of Wind-Plant Aerodynamics. In: 50th AIAA aerospace sciences meeting including the new horizons forum and aerospace exposition. American Institute of Aeronautics and Astronautics, Nashville, TN

Courtney M, Wagner R, Lindelöw P (2008) Testing and comparison of lidars for profile and turbulence measurements in wind energy. IOP Conf Ser Earth Environ Sci 1:012021. doi:10.1088/1755-1315/1/1/ 012021

Deardorff JW (1974a) Three-dimensional numerical study of the height and mean structure of a heated planetary boundary layer. Boundary-Layer Meteorol 7:81-106. doi:10.1007/BF00224974

Deardorff JW (1974b) Three-dimensional numerical study of turbulence in an entraining mixed layer. Boundary-Layer Meteorol 7:199-226. doi:10.1007/BF00227913

Dudhia J (1989) Numerical study of convection observed during the winter monsoon experiment using a mesoscale two-dimensional model. J Atmos Sci 46:3077-3107. doi:10.1175/1520-0469(1989)0462.0. $\mathrm{CO} ; 2$

Edwards JM, Beare RJ, Lapworth AJ (2006) Simulation of the observed evening transition and nocturnal boundary layers: single-column modelling. Q J R Meteorol Soc 132:61-80. doi:10.1256/qj.05.63

Fitch AC (2015) Notes on using the mesoscale wind farm parameterization of Fitch et al. (2012) in WRF. Wind Energy 19:1757-1758. doi:10.1002/we.1945

Fitch AC, Olson JB, Lundquist JK, Dudhia J, Gupta AK, Michalakes J, Barstad I (2012) Local and mesoscale impacts of wind farms as parameterized in a mesoscale NWP model. Mon Weather Rev 140:3017-3038. doi:10.1175/MWR-D-11-00352.1

Fitch AC, Lundquist JK, Olson JB (2013a) Mesoscale influences of wind farms throughout a diurnal cycle. Mon Weather Rev 141:2173-2198. doi:10.1175/MWR-D-12-00185.1

Fitch AC, Olson JB, Lundquist JK (2013b) Parameterization of wind farms in climate models. J Clim 26:6439_ 6458. doi:10.1175/JCLI-D-12-00376.1

Fleming PA, Gebraad PMO, Lee S, van Wingerden JW, Johnson K, Churchfield M, Michalakes J, Spalart P, Moriarty P (2014) Evaluating techniques for redirecting turbine wakes using SOWFA. Renew Energy 70:211-218. doi:10.1016/j.renene.2014.02.015

Fleming P, Gebraad PMO, Lee S, van Wingerden JW, Johnson K, Churchfield M, Michalakes J, Spalart P, Moriarty P (2015) Simulation comparison of wake mitigation control strategies for a two-turbine case. Wind Energy 18:2135-2143. doi:10.1002/we.1810

Fleming PA, Ning A, Gebraad PMO, Dykes K (2016) Wind plant system engineering through optimization of layout and yaw control. Wind Energy 19:329-344. doi:10.1002/we.1836 
Frandsen ST, Jørgensen HE, Barthelmie R, Rathmann O, Badger J, Hansen K, Ott S, Rethore PE, Larsen SE, Jensen LE (2009) The making of a second-generation wind farm efficiency model complex. Wind Energy 12:445-458. doi:10.1002/we.351

Grimsdell AW, Angevine WM (2002) Observations of the afternoon transition of the convective boundary layer. J Appl Meteorol 41:3-11. doi:10.1175/1520-0450(2002)041<0003:OOTATO>2.0.CO;2

Hansen KS, Barthelmie RJ, Jensen LE, Sommer A (2012) The impact of turbulence intensity and atmospheric stability on power deficits due to wind turbine wakes at Horns Rev wind farm. Wind Energy 15:183-196. doi:10.1002/we.512

Hong S-Y, Dudhia J, Chen S-H (2004) A revised approach to ice microphysical processes for the bulk parameterization of clouds and precipitation. Mon Weather Rev 132:103-120. doi:10.1175/15200493(2004)132<0103:ARATIM>2.0.CO;2

Howard KB, Singh A, Sotiropoulos F, Guala M (2015) On the statistics of wind turbine wake meandering: an experimental investigation. Phys Fluids 1994-Present 27:075103. doi:10.1063/1.4923334

Jacobson MZ, Delucchi MA, Cameron MA, Frew BA (2015) Low-cost solution to the grid reliability problem with $100 \%$ penetration of intermittent wind, water, and solar for all purposes. Proc Natl Acad Sci USA 112:15060-15065. doi:10.1073/pnas.1510028112

Jensen NO (1983) A note on wind generator interaction. Risø-M, No, p 2411

Jiménez PA, Navarro J, Palomares AM, Dudhia J (2015) Mesoscale modeling of offshore wind turbine wakes at the wind farm resolving scale: a composite-based analysis with the Weather Research and Forecasting model over Horns Rev. Wind Energy 18:559-566. doi:10.1002/we.1708

Kain JS (2004) The Kain-Fritsch convective parameterization: an update. J Appl Meteorol 43:170-181. doi:10. 1175/1520-0450(2004)043<0170:TKCPAU>2.0.CO;2

Katíc I, Højstrup J, Jenson NO (1986) A simple model for cluster efficiency. In: European wind energy association conference and exhibition, Rome, Italy

Keith DW, DeCarolis JF, Denkenberger DC, Lenschow DH, Malyshev SL, Pacala S, Rasch PJ (2004) The influence of large-scale wind power on global climate. Proc Natl Acad Sci USA 101:16115-16120. doi:10.1073/pnas.0406930101

Lothon M, Lohou F, Pino D, Couvreux F, Pardyjak ER, Reuder J, Vilà-Guerau de Arellano J, Durand P, Hartogensis O, Legain D, Augustin P, Gioli B, Lenschow DH, Faloona I, Yagüe C, Alexander DC, Angevine WM, Bargain E, Barrié J, Bazile E, Bezombes Y, Blay-Carreras E, van de Boer A, Boichard JL, Bourdon A, Butet A, Campistron B, de Coster O, Cuxart J, Dabas A, Darbieu C, Deboudt K, Delbarre H, Derrien S, Flament P, Fourmentin M, Garail A, Gibert F, Graf A, Groebner J, Guichard F, Jiménez MA, Jonassen M, van den Kroonenberg A, Magliulo V, Martin S, Martinez D, Mastrorillo L, Moene AF, Molinos F, Moulin E, Pietersen HP, Piguet B, Pique E, Román-Cascón C, Rufin-Soler C, Saïd F, Sastre-Marugán M, Seity Y, Steeneveld GJ, Toscano P, Traullé O, Tzanos D, Wacker S, Wildmann N, Zaldei A (2014) The BLLAST field experiment: boundary-layer late afternoon and sunset turbulence. Atmos Chem Phys 14:10931-10960. doi:10.5194/acp-14-10931-2014

Lundquist JK, Churchfield MJ, Lee S, Clifton A (2015) Quantifying error of lidar and sodar Doppler beam swinging measurements of wind turbine wakes using computational fluid dynamics. Atmos Meas Tech 8:907-920. doi:10.5194/amt-8-907-2015

MacDonald AE, Clack CTM, Alexander A, Dunbar A, Wilczak J, Xie Y (2016) Future cost-competitive electricity systems and their impact on US CO2 emissions. Nat Clim Change 6:526-531. doi:10.1038/ nclimate 2921

Magnusson M, Smedman AS (1994) Influence of atmospheric stability on wind turbine wakes. Wind Eng 18:139-152

Mahrt L (1981) The early evening boundary layer transition. Q J R Meteorol Soc 107:329-343. doi:10.1002/ qj.49710745205

Marquis M, Wilczak J, Ahlstrom M, Sharp J, Stern A, Smith JC, Calvert S (2011) Forecasting the wind to reach significant penetration levels of wind energy. Bull Am Meteorol Soc 92:1159-1171. doi:10.1175/ 2011BAMS3033.1

McLoughlin F, Duffy A, Conlon M (2013) Evaluation of time series techniques to characterise domestic electricity demand. Energy 50:120-130. doi:10.1016/j.energy.2012.11.048

Mirocha JD, Kosovic B, Aitken ML, Lundquist JK (2014) Implementation of a generalized actuator disk wind turbine model into the weather research and forecasting model for large-eddy simulation applications. J Renew Sustain Energy 6:013104. doi:10.1063/1.4861061

Mirocha JD, Rajewski DA, Marjanovic N, Lundquist JK, Kosović B, Draxl C (2015) Investigating wind turbine impacts on near-wake flow using profiling lidar data and large-eddy simulations with an actuator disk model. J Renew Sustain Energy 7:043143. doi:10.1063/1.4928873 
Mlawer EJ, Taubman SJ, Brown PD, Iacono MJ, Clough SA (1997) Radiative transfer for inhomogeneous atmospheres: RRTM, a validated correlated-k model for the longwave. J Geophys Res Atmos 102:1666316682. doi:10.1029/97JD00237

Nadeau DF, Pardyjak ER, Higgins CW, Fernando HJS, Parlange MB (2011) A simple model for the afternoon and early evening decay of convective turbulence over different land surfaces. Boundary-Layer Meteorol 141:301-324. doi:10.1007/s10546-011-9645-x

Nakanishi M, Niino H (2006) An improved Mellor-Yamada level-3 model: its numerical stability and application to a regional prediction of advection fog. Boundary-Layer Meteorol 119:397-407. doi:10.1007/ s10546-005-9030-8

Nieuwstadt FTM, Brost RA (1986) The decay of convective turbulence. J Atmos Sci 43:532-546. doi:10. 1175/1520-0469(1986)0432.0.CO;2

Rajewski DA, Takle ES, Lundquist JK, Oncley S, Prueger JH, Horst TW, Rhodes ME, Pfeiffer R, Hatfield JL, Spoth KK, Doorenbos RK (2013) Crop wind energy experiment (CWEX): observations of surface-layer, boundary layer, and mesoscale interactions with a wind farm. Bull Am Meteorol Soc 94:655-672. doi:10. 1175/BAMS-D-11-00240.1

Rajewski DA, Takle ES, Lundquist JK, Prueger JH, Pfeiffer RL, Hatfield JL, Spoth KK, Doorenbos RK (2014) Changes in fluxes of heat, H2O, and CO2 caused by a large wind farm. Agric For Meteorol 194:175-187. doi:10.1016/j.agrformet.2014.03.023

Rhodes ME, Lundquist JK (2013) The effect of wind-turbine wakes on summertime US midwest atmospheric wind profiles as observed with ground-based doppler lidar. Boundary-Layer Meteorol 149:85-103. doi:10.1007/s10546-013-9834-x

Sanderse B, van der Pijl S, p, Koren B (2011) Review of computational fluid dynamics for wind turbine wake aerodynamics. Wind Energy 14:799-819. doi:10.1002/we.458

Sastre M, Yagüe C, Román-Cascón C, Maqueda G (2015) Atmospheric boundary-layer evening transitions: a comparison between two different experimental sites. Boundary-Layer Meteorol. doi:10.1007/s10546015-0065-1

Sathe A, Mann J, Gottschall J, Courtney MS (2011) Can wind lidars measure turbulence? J Atmo Ocean Technol 28:853-868. doi:10.1175/JTECH-D-10-05004.1

Schmitz S (2012) XTurb-PSU: a wind turbine design and analysis tool. http://www.aero.psu.edu/Faculty_ Staff/schmitz/XTurb/XTurb.html. Accessed 31 Oct 2015

Skamarock WC, Klemp JB (2008) A time-split nonhydrostatic atmospheric model for weather research and forecasting applications. J Comput Phys 227:3465-3485. doi:10.1016/j.jcp.2007.01.037

Sorbjan Z (1997) Decay of convective turbulence revisited. Boundary-Layer Meteorol 82:503-517. doi:10. 1023/A:1000231524314

St. Martin CM, Lundquist JK, Clifton A et al (2017) Atmospheric turbulence affects wind turbine nacelle transfer functions. Wind Energy Sci. doi:10.5194/wes-2016-45

Stull RB (1988) An introduction to boundary layer meteorology. Kluwer Academic Publishers, Springer, $670 \mathrm{pp}$

Vanderwende B, Lundquist JK (2016) Could crop height affect the wind resource at agriculturally productive wind farm sites? Boundary-Layer Meteorol 158:409-428. doi:10.1007/s10546-015-0102-0

Vanderwende BJ, Lundquist JK, Rhodes ME, Takle ES, Irvin SL (2015) Observing and simulating the summertime low-level Jet in Central Iowa. Mon Weather Rev 143:2319-2336. doi:10.1175/MWR-D-1400325.1

Vanderwende BJ, Kosović B, Lundquist JK, Mirocha JD (2016) Simulating effects of a wind turbine array using LES and RANS. J Adv Model Earth Syst 8:1376-1390. doi:10.1002/2016MS000652

Wilczak JM, Oncley SP, Stage SA (2001) Sonic anemometer tilt correction algorithms. Boundary-Layer Meteorol 99:127-150. doi:10.1023/A:1018966204465

Wilczak J, Finley C, Freedman J, Cline J, Bianco L, Olson J, Djalalova I, Sheridan L, Ahlstrom M, Manobianco J, Zack J, Carley JR, Benjamin S, Coulter R, Berg LK, Mirocha J, Clawson K, Natenberg E, Marquis M (2015) The wind forecast improvement project (WFIP): a public-private partnership addressing wind energy forecast needs. Bull Am Meteorol Soc 96:1699-1718. doi:10.1175/BAMS-D-14-00107.1

Zhou L, Tian Y, Baidya Roy S, Thorncroft C, Bosart LF, Hu Y (2012) Impacts of wind farms on land surface temperature. Nat Clim Change 2:539-543. doi:10.1038/nclimate1505 